\title{
Edades de metamorfismo en las unidades con bajo grado de la región central del Famatina: la impronta del ciclo orogénico oclóyico (Ordovícico)
}

\author{
Gilda Collo ${ }^{1}$, Ricardo A. Astini ${ }^{1}$, Agustín Cardona ${ }^{2}$, Margarita D. Do Campo ${ }^{3}$, Umberto Cordani ${ }^{4}$ \\ ${ }^{1}$ Laboratorio de Análisis de Cuenca, CICTERRA, CONICET-UNC, Avenida Vélez Sársfield 1611, X5016GCA Córdoba, Argentina. \\ gildacollo@efn.uncor.edu; raastini@com.uncor.edu \\ 2 Centro de Investigaciones Tropicales Smithsonian, Ancon, Panamá. \\ cardonaa@si.edu \\ 3 INGEIS-UBA, Pabellón INGEIS, Ciudad Universitaria, 1428 Buenos Aires, Argentina. \\ marga@ingeis.uba.ar \\ ${ }^{4}$ Instituto de Geociências, Universidad de São Paulo, Brasil. \\ ucordani@usp.br
}

RESUMEN. Muchos de los episodios de metamorfismo y deformación asociados a las rocas de bajo grado del NO argentino fueron tradicionalmente vinculados con orógenos antiguos como el pampeano (Cámbrico) y el oclóyico (Ordovícico). En el cinturón del Famatina, la falta de dataciones precisas y de un análisis estratigráfico de detalle en las sucesiones con bajo grado, condujeron a interpretaciones ambiguas respecto a la evolución paleozoica del segmento sur de los Andes Centrales. Estudios recientes establecen que el 'basamento metamórfico' de bajo grado de dicha región estaría conformado por las formaciones Negro Peinado y Achavil, cuyos análisis de procedencia las vinculan con la finalización del ciclo pampeano. Por su parte, la Formación La Aguadita, también afectada por metamorfismo de bajo grado, correspondería a depósitos sinorogénicos ordovícicos (oclóyicos). En consecuencia, el conjunto sería más joven que la Formación Puncoviscana (prepampeana) con la que fue habitualmente correlacionado. Las edades K-Ar presentadas en este trabajo permiten establecer que el metamorfismo y la deformación de estas unidades son Ordovícicos y no más antiguos (Proterozoico-Cámbrico Medio) como se interpretó durante muchos años. Edades de $457 \pm 9 \mathrm{Ma}$ (roca total) y $463 \pm 14 \mathrm{Ma}$ (fracción $<2 \mu \mathrm{m}$ ) obtenidas para la Formación Negro Peinado, permiten su vinculación con el clímax de la orogenia oclóyica, desarrollada en el margen occidental de Gondwana durante el Paleozoico inferior. Las edades de

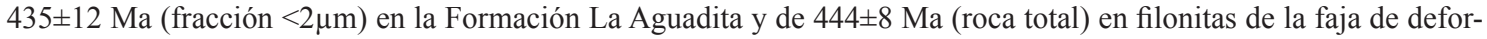
mación Angulos, son consistentes con la extensión de este ciclo orogénico hasta el Silúrico Inferior. Adicionalmente, se obtuvo una edad de $359 \pm 7$ Ma (fracción $<2 \mu \mathrm{m}$ ) en rocas de la Formación Negro Peinado (faja de deformación Las Trancas), que evidencia un reequilibrio local del sistema isotópico K-Ar parcialmente coincidente con el rango temporal asignado para la orogenia achaliana (Silúrico Tardío-Carbonífero temprano). 


\begin{abstract}
Metamorphic ages of low-grade units in the central region of Famatina: The signature of the Ocloyic Orogeny (Ordovician). Many of the metamorphic and deformational events associated to low-grade units in NW Argentina have been linked with ancient orogenies, like the Pampean (Cambrian) and the Ocloyic (Ordovician) cycles. The lack of specific ages in the low-grade metamorphic rocks of the Famatina belt, as well as the absence of a detailed stratigraphic analysis, have led to ambiguous interpretations respect to the Paleozoic evolution of the southern segment of the Central Andes. Recent work allows recognition of two units within the low-grade 'metamorphic basement'; the Negro Peinado and the Achavil formations. Provenance analysis relates deposition of both units to the final stages of the Pampean cycle during the Cambrian, whereas an Ordovician (Ocloyic) synorogenic nature is suggested for the La Aguadita Formation, also traditionally included within the low-grade 'metamorphic basement'. Thus, as a whole, these units are younger than the traditionally correlated pre-Pampean Puncoviscana Formation. K-Ar ages obtained for Famatina indicate that low-grade metamorphism and deformation of these units are Ordovician, in contrast to a much older age (Proterozoic-Middle Cambrian) previously suggested. Ages of $457 \pm 9 \mathrm{Ma}$ (whole rock) and $463 \pm 14 \mathrm{Ma}(<2 \mu \mathrm{m}$ fraction) for the Negro Peinado Formation allow establishing a link with the climax of the Ocloyic Orogeny developed along western Gondwana during the early Paleozoic. Ages of $435 \pm 12 \mathrm{Ma}(<2 \mu \mathrm{m}$ fraction $)$ in the La Aguadita Formation and of $444 \pm 8 \mathrm{Ma}$ (whole rock) in phyllonites of the Angulos shear zone are consistent with an extent into the earliest Silurian for this cycle. Additionally, a $359 \pm 7 \mathrm{Ma}(<2 \mu \mathrm{m}$ fraction) age for the Negro Peinado Formation (Las Trancas shear zone) indicates local resetting within the age range assigned to the Achalian Orogeny (Late Silurian-early Carboniferous).
\end{abstract}

Keywords: K-Ar ages, Low-grade metamorphism, Basement of Famatina, Andean foreland, Ocloyic Orogeny, Ordovician.

\section{Introducción}

Las sucesiones clásticas afectadas por bajo grado de metamorfismo afloran en el NO argentino como una franja relativamente continua que, fundamentalmente por sus similitudes litológicas y el grado metamórfico alcanzado, fue considerada una cuenca común denominada 'Cuenca Puncoviscana' (Zimmermann, 2005), desarrollada durante el Proterozoico Superior-Cámbrico Inferior en el margen occidental de Gondwana. En este contexto, unidades pertenecientes a formaciones como Puncoviscana, Suncho, La Cébila y La Aguadita fueron consideradas equivalentes (Aceñolaza y Aceñolaza, 2000, 2005; Aceñolaza et al., 2000; Aceñolaza, 2003; Zimmermann, 2003; Rossi et al., 2002). Los extensos afloramientos de rocas con bajo grado de metamorfismo del cinturón de Famatina, ubicado hacia el este de la faja corrida y plegada de la Precordillera en el actual antepaís andino del oeste argentino (Fig. 1), fueron considerados también parte de esta gran cuenca. Estas sucesiones, tradicionalmente asignadas a la Formación Negro Peinado, se consideraron como el 'basamento metamórfico' indiferenciado de la región, para el cual se sugirieron edades comprendidas entre el Proterozoico Tardío y Paleozoico temprano (De Alba, 1979; Rossi, 1996; Rossi et al., 1997a; Saavedra et al., 1998). Su principal episodio metamórfico-deformacional fue relacionado con un ciclo orogénico Paleozoico por Toselli (1975). Este autor (Toselli, 1978) sobre la base de dataciones $\mathrm{K}-\mathrm{Ar}$ en roca total sugirió que las rocas de dicha unidad habrían sido depositadas y metamorfizadas durante el Ordovícico Inferior. En contraste, autores como Aceñolaza y Toselli (1988) y Rossi et al. (1997a) establecieron, a partir de registros icnológicos, una edad de sedimentación más antigua (neoproterozoica-cámbrica temprana) y atribuyeron su metamorfismo al ciclo pampeano (Aceñolaza et al., 1990; Saavedra et al., 1998; Pankhurst y Rapela, 1998; Pankhurst et al., 1998). En este trabajo se usará la Escala de Tiempo Geológico de Gradstein et al. (2004).

A partir de un análisis detallado realizado sobre estas rocas con bajo grado de metamorfismo, Collo (2006) y Collo y Astini (en prensa) identificaron, además de la clásica Formación Negro Peinado, una nueva unidad denominada Formación Achavil. Edades U-Pb SHRIMP obtenidas en circones detríticos en dos muestras representativas de ambas unidades (Collo et al., 2005a) permitieron establecer que se habrían depositado con posterioridad al Cámbrico Medio y que representarían depósitos vinculados con la exhumación del orógeno pampeano ( $c a .530$ Ma, Rapela, 2000), como lo demuestra la población más joven ( ca. $520 \mathrm{Ma}$, con circones de hasta $504 \pm 16$ Ma, véase Collo et al., en prensa). En consecuencia, el metamorfismo que las afectó debería asociarse a un ciclo más joven.

Las rocas con bajo grado de metamorfismo de la Formación La Aguadita, ubicadas hacia el sector oriental del Famatina, fueron afectadas también por un episodio metamórfico-deformacional intenso, aunque la presencia de circones detríticos de $c a .480$ 


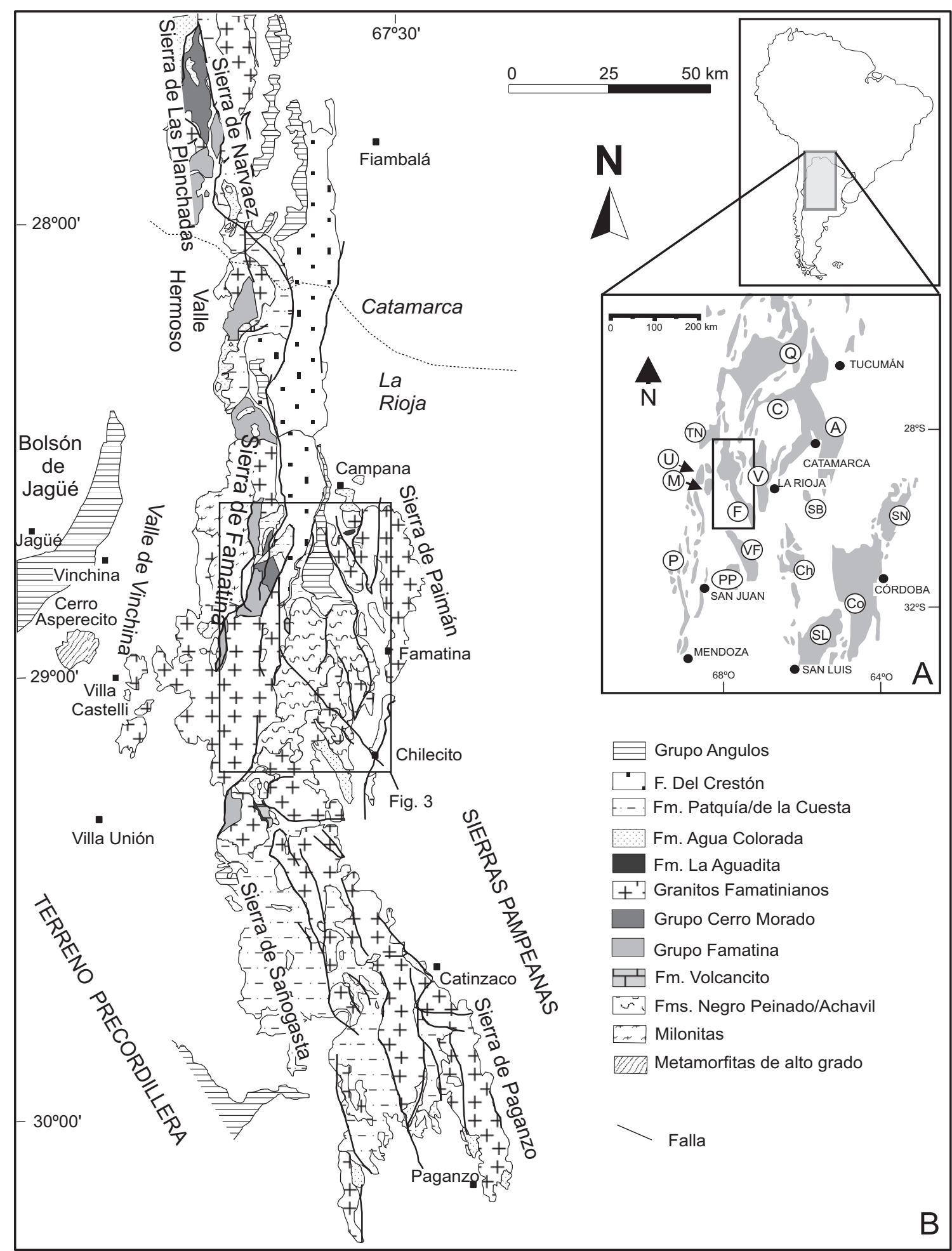

FIG. 1. a) Mapa de un segmento del actual antepaís andino entre $26^{\circ}$ y $33^{\circ} \mathrm{S}$. Q: Sierra de Quilmes; C: Capillitas; A: Ancasti; V: Velazco; F: Famatina; U: Umango; M: Sierra de Maz; TN: Toro Negro; VF: Valle Fértil; PP: Pie de Palo; Ch: Chepes y Llanos de La Rioja; SL: Sierras de San Luis; Co: Sierra de Córdoba; SN: Sierra Norte; SB: Sierra Brava; P: Faja plegada y corrida de Precordillera. b) Mapa geológico regional del Famatina. Se señala el área correspondiente a la figura 3 de mayor detalle. 
y $460 \mathrm{Ma}$ (Astini et al., 2003; Astini et al., 2005) indica que esta unidad no puede ser considerada parte del mencionado 'basamento metamórfico'. Dichos autores interpretan, en cambio, que se trataría de depósitos sinorogénicos del ciclo oclóyico. Esta interpretación ha sido recientemente sustentada por el hallazgo de faunas ordovícicas en unidades afectadas por metamorfismo de bajo grado interpuestas entre el Famatina y la región pampeana (Verdecchia et al., 2007). Si bien el episodio de metamorfismo que afectó a la Formación La Aguadita fue estudiado en detalle por Collo et al. (2005a) y Collo (2006), la edad del mismo aún no había sido establecida.

Sobre la base de la reciente actualización estratigráfica y caracterización metamórfica de las rocas con bajo grado del Famatina, se determinan edades $\mathrm{K}$-Ar en la fracción micácea $(<2 \mu \mathrm{m})$ y roca total de 5 muestras de metapelitas, que permiten establecer un ordenamiento temporal para los principales episodios metamórficos que afectaron la región.

\section{Marco Geológico}

El cinturón de Famatina está ubicado entre los $27^{\circ}$ y $31^{\circ} \mathrm{S}$, limitando al oeste con las sierras Pampeanas Occidentales y la faja corrida y plegada de la Precordillera y al este con los cordones pampeanos de las sierras de Velasco y Fiambalá (Fig. 1a). Si bien desde el Cenozoico el Famatina constituye parte del antepaís fragmentado (Dávila y Astini, 2007), durante el Paleozoico inferior constituyó un arco volcánico construido en el margen occidental de Gondwana (Toselli et al., 1996; Aceñolaza et al., 1996). Como consecuencia de la subducción de la placa pacífica desde el oeste y la posterior acreción continental de la microplaca de Precordillera se habría desarrollado una cuenca de retroarco (Astini y Dávila, 2004). La sucesión sedimentaria y volcano-sedimentaria asociada a esta cuenca cuya edad, demostrada en base al registro fósil, va desde el Cámbrico Tardío al Llanvirniano temprano a medio (Astini, 1999, 2003), se deposita en discordancia angular sobre rocas con bajo grado de metamorfismo (Fig. 2). Todo el conjunto se encuentra parcialmente intruido por granitoides ordovícicos ( $c a$. 481-460 Ma, Pankhurst et al., 2000; Dahlquist et al., 2005a) y rocas filonianas de variada naturaleza (pórfidos félsicos y lamprófiros) (Toselli et al., 1996; Pankhurst et al., 2000) que, localmente, producen metamorfismo de contacto en las rocas de caja (Rossi, 1996; Cisterna et al., 1990; Durand et al., 1990).
Las sucesiones afectadas por bajo grado de metamorfismo en la región central del Famatina están representadas por las formaciones Negro Peinado, Achavil y La Aguadita. Sin embargo, la reciente reinterpretación estratigráfica de esta última (Astini et al., 2003, 2005) permite sostener que el conjunto de unidades ordovícicas del Famatina se habría depositado sólo sobre las formaciones Negro Peinado y Achavil (Figs. 2 y 3). Esta relación ha sido cartografiada (Collo, 2006) en la quebrada del río Volcancito donde la unidad homónima (Cámbrico Tardío-Ordovícico Temprano) se apoya en discordancia angular sobre la Formación Achavil (Figs. 2 y 3$)$.

\subsection{Metamorfismo de las formaciones Negro Peinado, Achavil y La Aguadita}

Los episodios de metamorfismo por los que fueron afectadas las formaciones Negro Peinado, Achavil y La Aguadita fueron caracterizados por Collo (2006) y Collo et al. (2005b).

La Formación Negro Peinado (Fig. 4a), cuya edad de sedimentación pudo acotarse entre el Cámbrico Medio y el Ordovícico Temprano (Collo et al., 2005a, Collo y Astini, en prensa), fue afectada por un evento metamórfico-deformacional $\mathrm{M} 1_{\mathrm{NP}}-\mathrm{D} 1_{\mathrm{NP}}$ con desarrollo de un plegamiento intrafoliar intenso (Fig. 5a, b). Los análisis de DRX permitieron establecer que la fracción arcillosa neoformada, vinculada al episodio de máximo soterramiento, se compone de illita, clorita y ocasionalmente biotita (Figs. 5c, d). Por lo general, la illita es la fase predominante $(\sim 90 \%)$, aunque en algunas muestras los contenidos de clorita son importantes $(\sim 50 \%)$. El metamorfismo se ubica en la anquizona intensa-epizona (IK: 0,16-0,28 $\Delta^{\circ} 2 \theta$ ) hasta la zona de biotita (desarrollo de biotita blástica, Fig. $5 \mathrm{c}$, d), con temperaturas estimadas entre $290^{\circ}$ y $400^{\circ} \mathrm{C}$ (Collo, 2006). Análisis EDX ('energy-dispersive system') realizados en muestras de esta unidad, arrojaron contenidos de sílice de hasta 3,33 a.p.f.u. para las micas blancas (libres de sustitución illítica) asociadas al metamorfismo. De acuerdo a Massone y Szpurka (1997) los contenidos de sílice en rocas con ausencia de paragénesis limitante (cuarzo, feldespato potásico y flogopita) pueden ser utilizados para establecer condiciones de presiones mínimas para una secuencia. Según estos autores contenidos de 3,33 a.p.f.u. representarían fases generadas a presiones de $\sim 4,5 \mathrm{~kb}$. El parámetro b de la mica blanca 


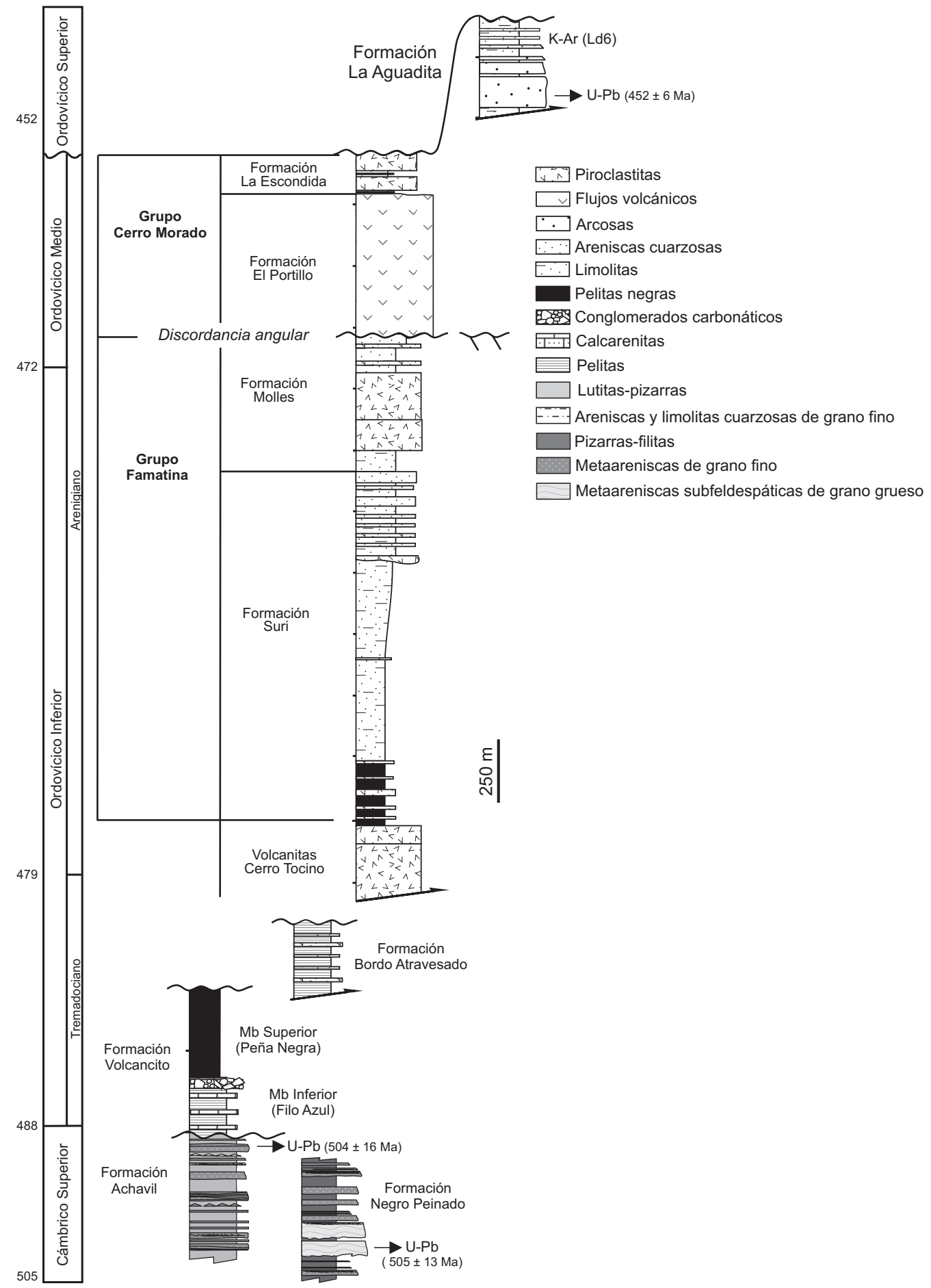

FIG. 2. Columnas estratigráficas para las unidades del Paleozoico inferior en el cinturón del Famatina (modificada de Astini, 2003). Se señalan los niveles de los que proceden las edades U-P SHRIMP sobre circones detríticos (Astini et al., 2003; Collo et al., 2005b) puntualizando las edades individuales más jóvenes. Se indica, además, el nivel de la Formación La Aguadita en el que se realizó uno de los análisis K-Ar presentados en este trabajo. La deformación que afecta a la Formación Negro Peinado impide ubicar con exactitud la posición estratigráfica de los niveles analizados en esta unidad, por lo que no son señalados en esta figura. 


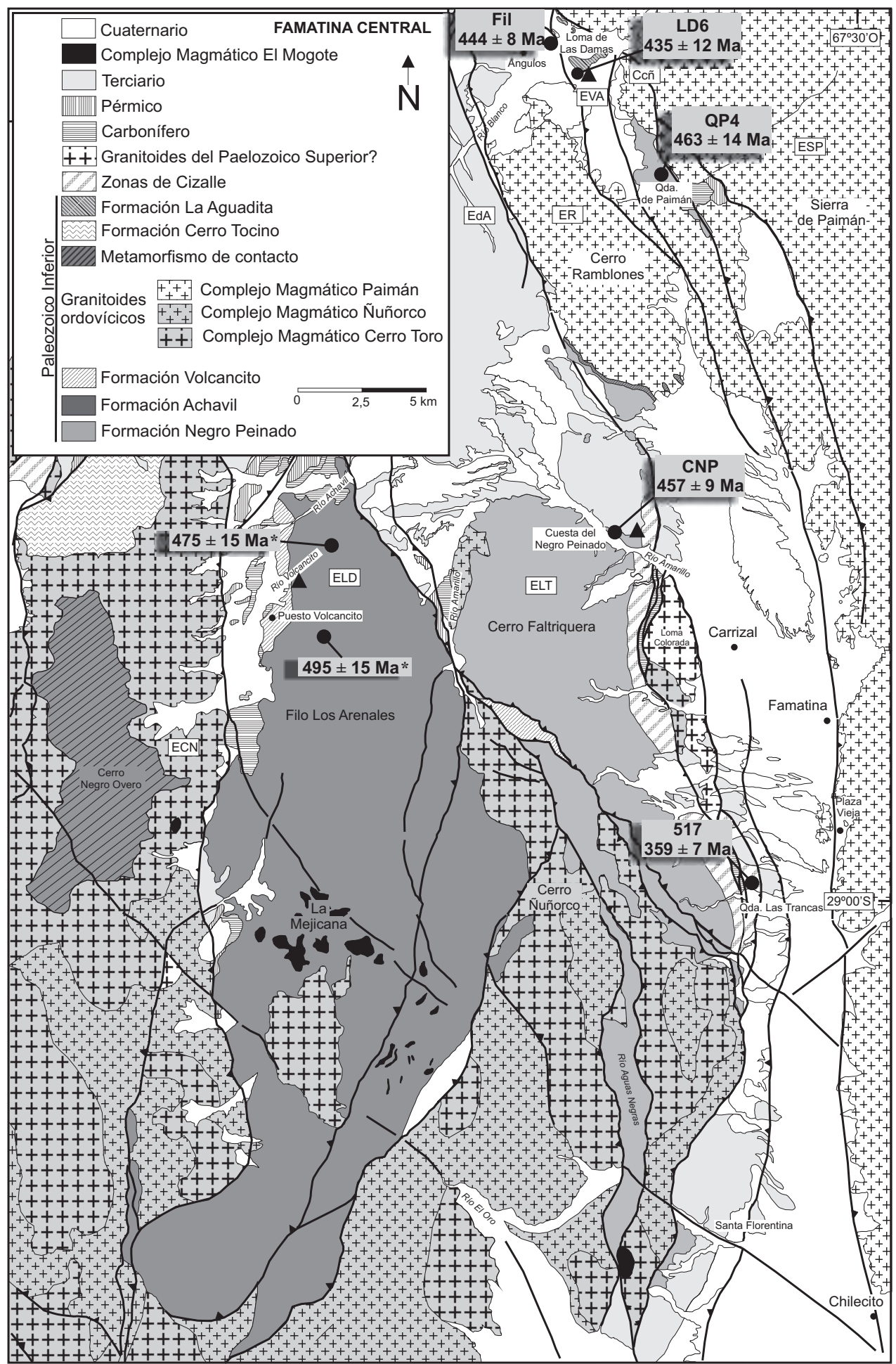

FIG. 3. Mapa geológico de la región central de Famatina (modificado de Collo, 2006); EVA: Escama Valle de La Aguadita; Ceñ: Corrimiento Chañarmuyo; ESP: Escama Sierra de Paimán; ER: Escama Ramblones; EdA: Escama del Abra; ELT: Escama Las Trancas; ELD: Escama Los Damascos; ECN: Escama del Cordón de los Nevados. * Muestra analizada por Toselli (1978). Con tres triángulos negros se señalan las localidades de donde proceden las edades U-Pb SRHIMP mencionadas en el trabajo. 
(b: 9,025 Á, n: 7 s: 0,004, Tabla 1) medido en las mismas rocas es característico de la serie de presión media (con un gradiente de $25-35^{\circ} \mathrm{C} / \mathrm{km}$, Guidotti y Sassi, 1986; Merriman y Frey, 1999; Merriman, $2002,2005)$ y consistente con las presiones estimadas a partir del quimismo de las fengitas.

Tanto las presiones y gradientes establecidos, así como la disposición textural de los filosilicatos transformados y neoformados (incluyendo la biotita, Fig. 5c, d), que definen la foliación metamórfica, permitieron desvincular el metamorfismo que afecta a esta unidad de un metamorfismo de contacto asociado a la intrusión de los granitoides ordovícicos. Esto no descarta que el gradiente térmico regional haya estado relativamente elevado dado el contexto de arco de la región. Los efectos de un metamorfismo de contacto pueden acotarse a las zonas periféricas de los granitoides (Rossi et al., 1997b). Asimismo, la presencia localizada de esquistos cordieríticos con una foliación metamórfica clara (SE del Cerro Ramblones, Fig. 3), es consistente con un desarrollo sincrónico entre el metamorfismo regional dominante y la intrusión de algunos de los cuerpos graníticos.

En la Formación Negro Peinado se identificaron además zonas de cizalle discretas, asociadas con un episodio $\mathrm{M} 2_{\mathrm{NP}}-\mathrm{D} 2_{\mathrm{NP}}$ superpuesto al episodio principal M1 ${ }_{\mathrm{NP}}-\mathrm{D} 1_{\mathrm{NP}}($ Collo, 2006). Este segundo episodio afecta, particularmente, a las rocas que forman la parte oriental de la escama de Las Trancas (Fig. 3).

Para la Formación Achavil (Fig. 4b), con una edad límite de depositación cámbrica media a superior (504 $\pm 16 \mathrm{Ma}$, edad U-Pb SHRIMP del circón más joven, Collo et al., 2005a), los valores de IK medidos $\left(0,26-0,41 \Delta^{\circ} 2 \theta\right)$ indican que fue metamorfizada bajo condiciones de anquizona débil a intensa, con temperaturas estimadas entre $200^{\circ}$ y $280^{\circ} \mathrm{C}$ para el clímax del metamorfismo (Tabla 1, Fig. 5e). Para esta formación se identificaron dos episodios de plegamiento superpuestos. El más antiguo, demoninado $\mathrm{P} 1_{\mathrm{A}}$, se orienta $\sim \mathrm{E}-\mathrm{O}$, mientras que el segundo, denominado $\mathrm{P} 2$, se orienta $\sim \mathrm{N}-\mathrm{S}$ (Collo et al., 2006). Ambos plegamientos presentan rasgos indicativos de deformaciones en niveles estructurales relativamente altos $(<5 \mathrm{~km})$, por lo que resulta probable que el máximo soterramiento haya sido alcanzado por las rocas de esta unidad con posterioridad a los episodios de deformación indicados. Esto resulta, a su vez, consistente con las condiciones de máximo soterramiento establecidas
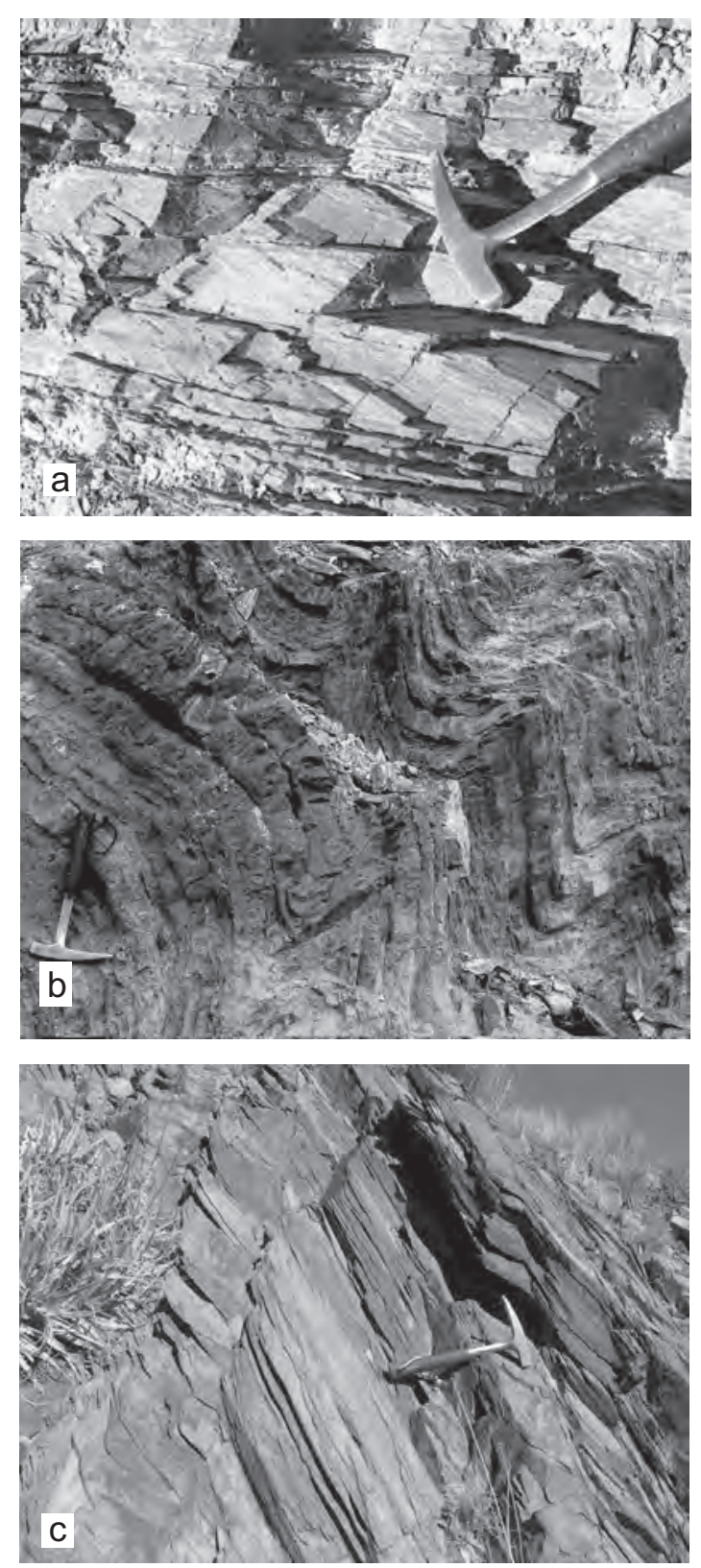

FIG. 4.a. Afloramiento de la Formación Negro Peinado en el que puede observarse el desarrollo intenso de la foliación metamórfica S1 con recristalización mineral asociada; b. Formación Achavil en el flanco oeste del Filo los Arenales. Obsérvese la alternancia de niveles pelíticos y arenosos y el plegamiento de gran longitud de onda por el que está afectada la unidad; c. Formación La Aguadita, sección perteneciente al miembro superior en el que alternan bancos centimétricos de metaareniscas y metapelitas resaltados por la refracción del clivaje que corta la sucesión con un ángulo relativamente alto. 
para las rocas de la Formación Volcancito, carentes de deformación apreciable $\left(210^{\circ}\right.$ a $240^{\circ} \mathrm{C}$, Collo, 2006) y depositadas en discordancia angular sobre la Formación Achavil.

El parámetro b de la mica blanca indica que en la región del río Volcancito el máximo soterramiento de la Formación Achavil habría tenido lugar bajo condiciones de presión intermedia a intermediabaja (b: 9,011 $\AA, \mathrm{n}: 6, \mathrm{~s}: 0,004)$ con un gradiente geotérmico de $\sim 30-35^{\circ} \mathrm{C} / \mathrm{km}$ (Tabla 1). Estos valores son consistentes con el quimismo de las micas blancas establecido mediante EDX, con contenidos máximos de Si de 3,32 a.p.f.u. que, en ausencia de la paragénesis limitante mencionada, indicarían presiones mínimas de entre 2,5 y $3 \mathrm{~kb}$ (cf. Massonne y Szpurka, 1997). Los análisis de DRX realizados para las pizarras de la Formación Achavil, evidenciaron que, en todos los casos, la fracción $<2 \mu \mathrm{m}$ se compone principalmente de illita (68 a $98 \%$ de los filosilicatos), con clorita subordinada (2 a 32\%). En unas pocas muestras se identificaron cantidades menores interestratificadas de clorita/vermiculita $(\mathrm{Chl} / \mathrm{Vm})$ y de esmectita (4\%) que corresponderían al producto de reacciones retrógradas locales, dado que fases de este tipo no son por lo general estables en la anquizona débil a intensa y la región está afectada por hidrotermalismo relativamente reciente.
Las rocas de la Formación La Aguadita (Fig. 4c) estuvieron sometidas al menos a dos procesos posdeposicionales claramente identificables. Durante el primero de ellos, de mayor intensidad y el que mejor se preserva, tuvo lugar una blástesis mineral, asociada al desarrollo de un clivaje $\mathrm{S}_{1}$ (Fig. 5f). Los análisis de DRX realizados sobre la fracción arcilla de las metapelitas indican que la illita es el principal mineral formado durante este episodio (61 a 94\%), acompañado por clorita poco abundante (4 a $9 \%$ ), mientras que el estudio microscópico evidenció la recristalización de minerales cuarzo-feldespáticos. Los valores del IK obtenidos indican que este episodio tectono-metamórfico alcanzó el campo de la anquizona ( $\left.\mathrm{IK}=0,25-0,40 \Delta^{\circ} 2 \theta\right)$, con temperaturas estimadas entre $200^{\circ}$ y $300^{\circ} \mathrm{C}$ (Tabla 1). El parámetro b de la mica blanca ( $b$ : $9,025 \AA$; $\mathrm{n}: 3$, s: $0,003)$ corresponde a la serie de facies de presión intermedia propuesta por Guidotti y Sassi (1986), con un gradiente geotérmico estimado de entre $25^{\circ}$ y $30^{\circ} \mathrm{C}$. Estos valores son consistentes con el contenido de $\mathrm{Si}$ en las micas blancas; el valor máximo de 3,38 a.p.f.u. correspondería a presiones de $\sim 3,5$ $\mathrm{Kb}$ que, debido a que en estas rocas se identificó la paragénesis limitante, puede ser interpretada como la máxima presión a la que fue sometida durante su soterramiento.

TABLA 1. INDICADORES DE LAS CONDICIONES DE SOTERRAMIENTO DE LAS UNIDADES CON BAJO GRADO DE METAMORFISMO DEL FAMATINA.

\begin{tabular}{ccccc}
\hline Formación & $\mathbf{I K}\left(\Delta^{\circ} \mathbf{2 \theta}\right)$ & Temperatura $\left({ }^{\circ} \mathbf{C}\right)$ & Parámetro b $(\AA)$ & Serie de Facies de Presión \\
\hline \multirow{2}{*}{ Negro Peinado } & $0,16-0,28$ & & & Intermedia \\
& n: 5, s: 0,05 & $290-400$ & n: $7,025: 0,004$ & $25-35^{\circ} \mathrm{C} / \mathrm{km}$ \\
Achavil & $0,26-0,41$ & & 9,011 & Intermedia/Intermedia -baja \\
& n: $11, \mathrm{~s}: 0,06$ & $200-280$ & n: $6, \mathrm{~s}: 0,004$ & $30-35^{\circ} \mathrm{C} / \mathrm{km}$ \\
La Aguadita & $0,25-0,40$ & \multirow{2}{*}{$200-300$} & 9,025 & Intermedia \\
& n: $8, \mathrm{~s}: 0,03$ & & n: $3, \mathrm{~s}: 0,003$ & $25-35^{\circ} \mathrm{C} / \mathrm{km}$ \\
\hline
\end{tabular}

Las temperaturas y gradientes son estimados a partir de los valores de IK y del parámetro b de la mica blanca. Las series de facies de presión son

las propuestas por Guidotti y Sassi (1986).

FIG. 5. Microfotografías. Formación Negro Peinado: a. bandas filosilicáticas y cuarzosas alternantes que reflejan el bandeado composicional primario y son coincidentes con la orientación de la foliación metamórfica S1 asociada al plegamiento P1 del episodio $\mathrm{M} 1_{\mathrm{NP}}-\mathrm{D} 1_{\mathrm{NP}}$ (nicoles cruzados), b. banda filosilicática de grano fino plegada en una capa de grano más grueso; obsérvese la intensa recristalización en los dominios, $\mathbf{c}$. $\mathbf{y}$ d. desarrollo de biotita blástica definiendo la foliación principal de la roca (nicoles paralelos), observar en $\mathbf{d}$ algunos cristales asociados a las sombras de presión de los granos de cuarzo. Formación Achavil: e. metaarenisca cuarzosa con la foliación metamórfica $\mathrm{S} 1$ asociada al plegamiento $\mathrm{P} 1_{\mathrm{A}}$, evidenciada por la orientación de los granos de cuarzo y los filosilicatos de la matriz (nicoles cruzados); Formación La Aguadita: f. metagrauvaca en la que se observan los cristales cuarzo-feldespáticos rodeados por una matriz cuarzo-micácea que define la foliación S1 generada durante el episodio M1 ${ }_{\mathrm{LA}}-\mathrm{D} 1_{\mathrm{LA}}$ (nicoles cruzados); Faja Milonítica Angulos: g. y h. filonita en la que pueden observarse bandas producto de recristalización mineral con blástesis de biotita (nicoles paralelos). 

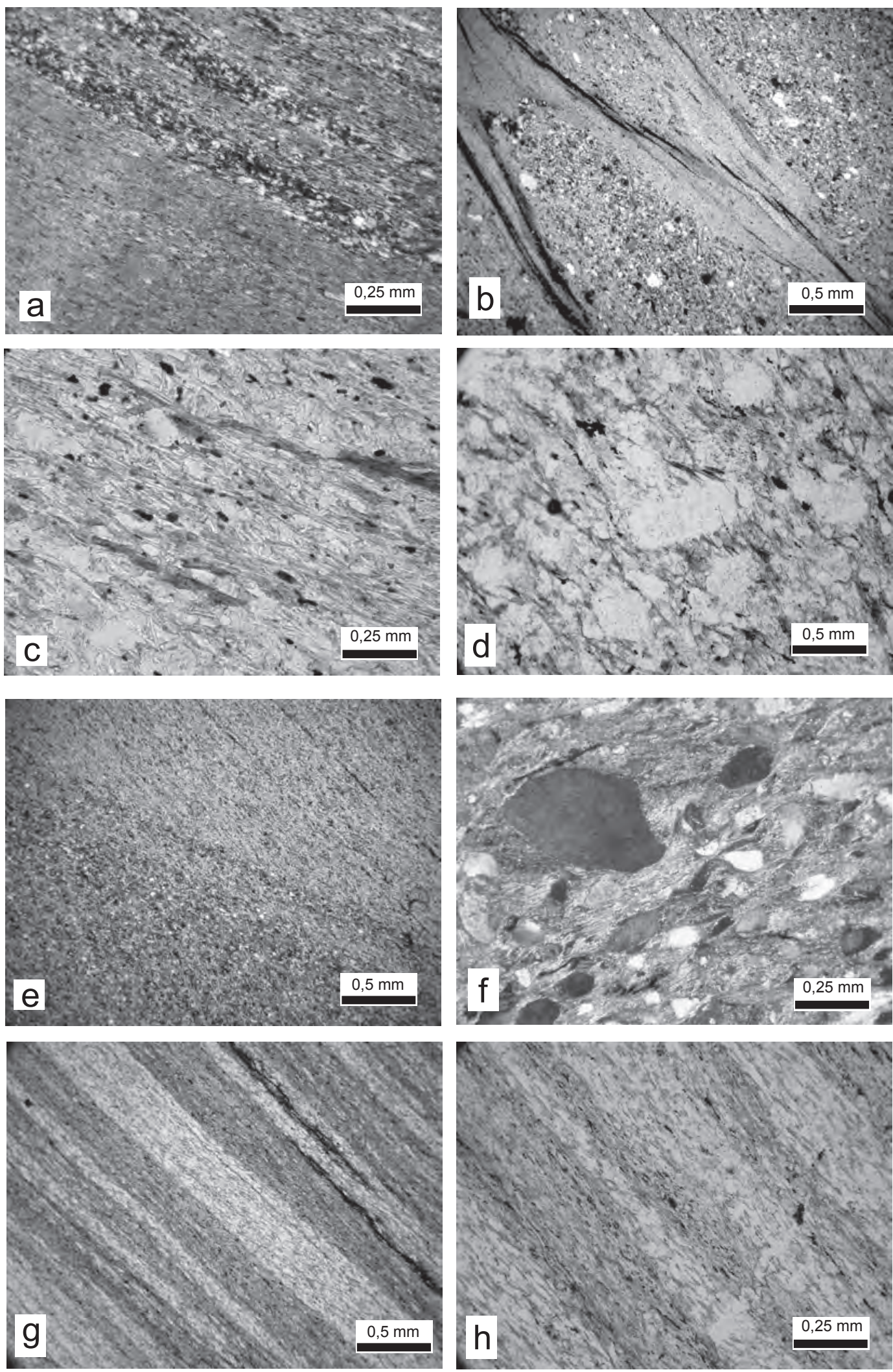
La edades U-Pb SHRIMP en circones detríticos de esta unidad (Astini et al., 2003; Tabla 2) permiten establecer una edad máxima ordovícica superior para el metamorfismo por el que fue afectada (edades más jóvenes de $452 \pm 6$ y $458 \pm 5 \mathrm{Ma}$ ).

El segundo proceso identificado en la Formación La Aguadita es posterior al episodio tectonometamórfico principal y consiste en una alteración hidrotermal de tipo propilítica, vinculada a zonas marginales de un sistema de alteración. Durante este episodio tuvo lugar la blástesis de epidota y clorita en las rocas de grano más grueso. En las metapelitas se identificó escasa esmectita generada durante un evento de retrodiagénesis, que podría vincularse con la circulación de fluidos de baja temperatura $\left(<180^{\circ} \mathrm{C}\right)$ durante las etapas póstumas de la alteración hidrotermal o bien con la interacción de las rocas con agua meteórica durante el ascenso de la unidad (Collo et al., 2005b).

\section{TABLA 2. EDADES U-PB SHRIMP EN CIRCONES DETRÍ-} TICOS DE LA FORMACIÓN LA AGUADITA.

\begin{tabular}{ccr}
\hline & \multicolumn{2}{c}{$\mathbf{E d a d}(\mathbf{M a})$} \\
Grano & ${ }^{206} \mathbf{P b}{ }^{\mathbf{2 3 8}} \mathbf{U}$ & $\mathbf{( \sigma )}$ \\
\hline 1,1 & 457,6 & 4,9 \\
2,1 & 463,4 & 5,7 \\
3,1 & 470,7 & 6,5 \\
4,1 & 485,7 & 5,4 \\
5,1 & 483,1 & 6,0 \\
6,1 & 472,5 & 5,6 \\
7,1 & 468,7 & 5,6 \\
8,1 & 480,1 & 5,3 \\
9,1 & 451,5 & 5,5 \\
10,1 & 481,0 & 5,3 \\
11,1 & 480,9 & 5,3 \\
12,1 & 464,2 & 4,9 \\
13,1 & 483,4 & 5,6 \\
14,1 & 451,8 & 22,7 \\
15,1 & 477,8 & 5,6 \\
16,1 & 490,1 & 5,2 \\
17,1 & 483,7 & 5,5 \\
\hline
\end{tabular}

\section{Muestreo y Métodos Analíticos}

Las mediciones K-Ar se realizaron en 4 pelitas pertenecientes a las formaciones Negro Peinado y La Aguadita; además, se realizó una medición en una muestra de la filonita de la faja de deformación Angulos (Dávila et al., 2003; Astini y Dávila, 2004), ubicada inmediatamente al oeste e infrayaciendo a la Formación La Aguadita (Fig. 3). Dos de las muestras analizadas en la Formación Negro Peinado (QP4: $28^{\circ} 42^{\prime} 38,7^{\prime \prime S}-67^{\circ} 35^{\prime} 50^{\prime \prime O}$ y CNP: $28^{\circ} 50^{\prime} 49,3^{\prime \prime S}-$ $67^{\circ} 37^{\prime} 13,2$ "O) fueron tomadas en regiones afectadas únicamente por el episodio $\mathrm{M} 1_{\mathrm{NP}}-\mathrm{D} 1_{\mathrm{NP}}$, mientras que la restante (517: 28 $\left.8^{\circ} 59^{\prime} 27,1^{\prime \prime S}-67^{\circ} 33^{\prime} 49^{\prime \prime O}\right)$ corresponde a una de las regiones afectadas por la faja de cizalle (Fig. 3). En ningún caso las muestras presentan evidencias de haber sido afectadas por el metamorfismo de contacto generado por los intrusivos ordovícicos. La muestra de la Formación La Aguadita (LD6) fue tomada en la localidad de Loma de Las Damas (2839'45,9"S-67³8'01'O, Fig. 3). $\mathrm{El}$ análisis isotópico de la filonita (Fil), formada a partir de un granitoide, se realizó sobre roca total en una muestra tomada de la localidad tipo (Fig. 3, Dávila, 2001).

En tres de las muestras pelíticas (QP4, 517 y LD6) los análisis K-Ar fueron realizados sobre la fracción $<2 \mu \mathrm{m}$, para minimizar la presencia de fases detríticas portadoras de $\mathrm{K}$ (micas y feldespatos) que pudieran contener Ar heredado. La separación se realizó siguiendo las recomendaciones de Moore y Reynolds (1997) y Kisch (1991). Cabe aclarar que para la saturación de los filosilicatos se utilizó acetato de $\mathrm{Na}^{+}$, dado que el mismo no interfiere en la determinación de las relaciones isotópicas del $\mathrm{Ar}$ en el espectrómetro de masas. Asimismo, en el caso de las esmectitas, este catión remueve el $\mathrm{K}^{+}$de sitios intercambiables en donde el Ar radiogénico no es retenido. En las dos muestras restantes (CNP y Fil), que presentaban blástesis de biotita, las mediciones se realizaron sobre la roca total.

Los análisis K-Ar fueron realizados en el Laboratorio Ar/Ar del Centro de Investigaciones Geocronológicas de la Universidad de São Paulo según el protocolo de Cordani (1970) y Cordani et al. (2004). La mineralogía de la fracción arcilla de las metapelitas sobre la que se realizaron 3 de las mediciones, se determinó en el INGEIS empleando un difractómetro Philips equipado con un goniómetro vertical PW1050. Los análisis por difracción de rayos $\mathrm{X}$ se realizaron sobre los agregados orientados (a.o.) secados al aire entre 3 y $50^{\circ} 2 \theta$, de los a.o. tratados con etilen-glicol durante 12 horas a $60^{\circ} \mathrm{C}$ y después de calentados a $500^{\circ} \mathrm{C}$ durante 4 horas, entre 3 y $30^{\circ} 2 \theta$. Las condiciones de las corridas fueron $50 \mathrm{kV}$ y 30 $\mathrm{mA}$, a una velocidad de $1 \%$ min. Además, en estas muestras se midió el índice de Kübler(IK), parámetro basado en la medición del ancho a la altura media de la reflexión (001) de la mica blanca y que se emplea para establecer las condiciones de soterramiento alcanzadas por una unidad (Kübler, 1968; Guggenheim et al., 2002). Para poder convertir las mediciones 
del IK a la escala internacional 'crystallinity index standard' (CIS), propuesta por Warr y Rice (1994), se trataron los patrones suministrados por dichos autores siguiendo los mismos procedimientos que se emplearon para tratar las muestras problema (Kisch, 1991). Con los valores de IK obtenidos para los patrones se calculó la ecuación de regresión para el difractómetro utilizado (CIS $=1,151 \mathrm{x}+0,0071 \Delta^{\mathrm{o}} 2 \theta$, r: 0,9963). En la escala CIS los límites inferior y superior de la anquizona son respectivamente 0,42 y $0,25 \Delta^{\circ} 2 \theta$. Se realizaron cuatro mediciones del IK para cada muestra, dos sobre el preparado original y dos sobre el duplicado, promediándose los cuatro valores obtenidos. Las corridas para la medición del IK se realizaron a $40 \mathrm{kV}$ y $30 \mathrm{~mA}$, a una velocidad de $0,5^{\circ} / \mathrm{min}$ entre 7,5 y $10^{\circ} 2 \theta$.

\section{Resultados: Características mineralógicas y relaciones $\mathrm{K}$-Ar de las muestras analizadas}

\subsection{Formación Negro Peinado}

\subsubsection{Muestras afectadas por el episodio meta- mórfico principal $M 1_{N P}-D 1_{N P}$}

En la muestra QP4 la mineralogía de la fracción $<2 \mu \mathrm{m}$ se compone predominantemente de illita (67\%) y clorita (33\%), con cuarzo y albita subordinados, mientras que no se identificó biotita blástica (Tabla 3, Fig. 6a). En esta metapelita el IK medido es de $0,27 \Delta^{\circ} 2 \theta$, correspondiendo a la parte superior de la anquizona intensa. La edad K-Ar obtenida para esta muestra es de $463 \pm 14$ Ma (Tabla 4). La muestra CNP es una metapelita con clara blástesis de biotita (Fig. 5c), cuya mineralogía se compone predominantemente de illita, biotita, clorita, cuarzo y albita, con pequeñas concentraciones $(<5 \%)$ de interestratificado I/S y de esmectita (Tabla 3, Fig. 6d), ambas producto de alteración local, probablemente asociada a la exhumación de la secuencia. Para esta muestra de roca total se obtuvo una edad K-Ar de 457 \pm 9 Ma (Tabla 4).

\subsubsection{Muestra afectada por los episodios $M 1_{N P}$ - $D 1_{N P} y M 2_{N P}-D 2_{N P}$}

La fracción $<2 \mu$ m de la muestra 517 está formada predominantemente por illita (78\%) y clorita (22\%), con cuarzo y albita subordinados (Fig. 6b, Tabla 3 ). El IK medido de $0,28 \Delta^{\circ} 2 \theta$ corresponde a la parte superior de la anquizona intensa. Para la misma se

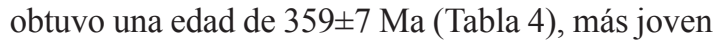
que las obtenidas para las muestras QP4 y CNP.
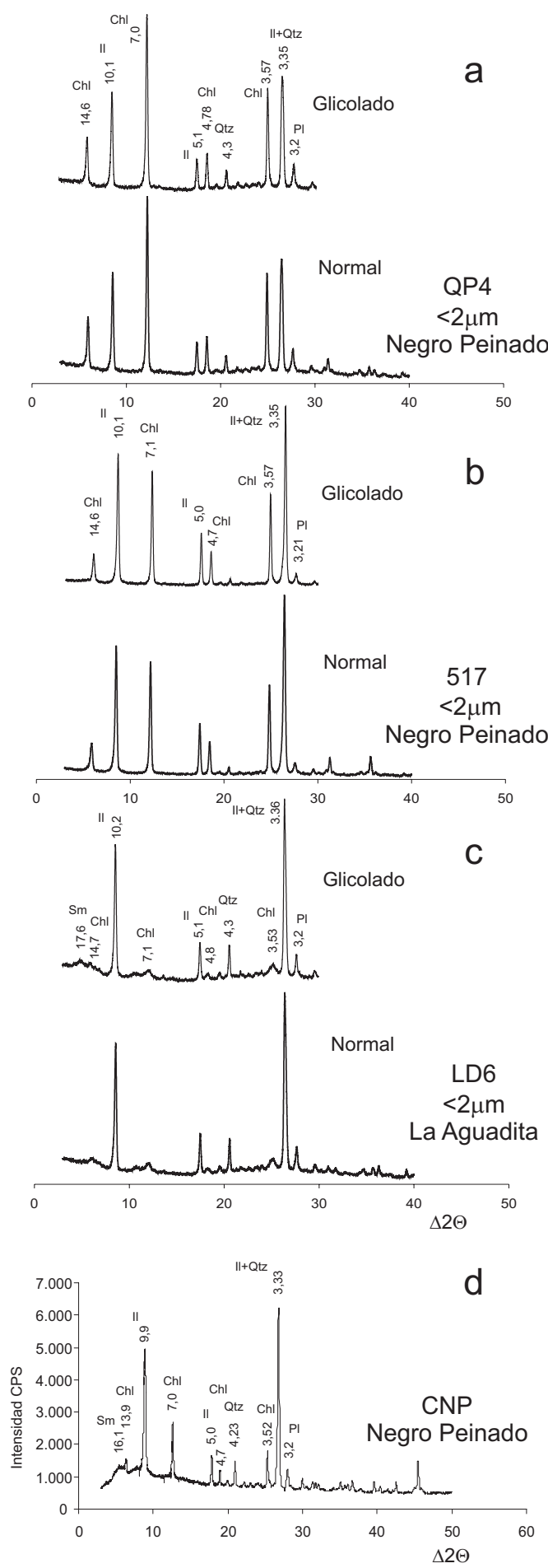

FIG. 6. Mineralogía de la fracción arcilla $(<2 \mu \mathrm{m})$ establecida mediante DRX sobre agregados orientados secados al aire y glicolados de las muestras pertenecientes a las formaciones Negro Peinado (a y b) y La Aguadita (c) analizadas isotópicamente; d) análisis deDRX de roca total en la muestra CNP de la Formación Negro Peinado. 
TABLA 3. COMPOSICIÓN DE LAS MUESTRAS ANALIZADAS. LOS VALORES REPRESENTAN PORCENTAJES RELATIVOS A LA FRACCIÓN DE MINERALES DE ARCILLA.

\begin{tabular}{cccccccccc}
\hline Muestra & $\begin{array}{c}\text { Tipo de } \\
\text { material }\end{array}$ & Illita & Esmectita & Illita/esmectita & Clorita & Biotita & Cuarzo & Albita & IK \\
\hline CNP (NP) & Roca total & $90^{*}$ & $i ?$ & $i ?$ & 10 & $90^{*}$ & $\checkmark$ & $\checkmark$ & - \\
$\mathbf{5 1 7}$ (NP) & $<2 \mu \mathrm{m}$ & 78 & - & - & 22 & - & $\checkmark$ & $\checkmark$ & 0,28 \\
QP4 (NP) & $<2 \mu \mathrm{m}$ & 67 & - & - & 33 & - & $\checkmark$ & $\checkmark$ & 0,27 \\
LD6 (LA) & $<2 \mu \mathrm{m}$ & 89 & 3 & $i ?$ & 9 & - & $\checkmark$ & $\checkmark$ & 0,26 \\
Filonita & Roca total & $\checkmark$ & - & - & $\checkmark$ & $\checkmark$ & $\checkmark$ & $\checkmark$ & - \\
\hline
\end{tabular}

Se indican en forma complementaria con un $\checkmark$ las fases filosilicáticas no cuantificadas y las fases no filosilicáticas presentes. ¿?: presencia dudosa, -:ausente. Los valores de IK están expresados en $\Delta^{\circ} 2 \theta$. Los valores indicados con * corresponden a illita y biotita sin discriminar durante la cuantificación. Para la filonita se indican sólo las fases minerales presentes. NP: Formación Negro Peinado; LA: Formación La Aguadita.

TABLA 4. ANÁLISIS ISOTÓPICOS K-Ar EN ROCAS DE LAS FORMACIONES NEGRO PEINADO, LAAGUADITA Y EN UNA MUESTRA DE FILONITA DE LA FAJA MILONÍTICA ANGULOS.

\begin{tabular}{|c|c|c|c|c|c|c|c|}
\hline Muestra & $\begin{array}{c}\text { Fracción } \\
\text { analizada }\end{array}$ & $\%$ de $\mathrm{K}$ & $\begin{array}{l}\text { Error } \\
K(\%)\end{array}$ & $\begin{array}{c}A r^{40} \operatorname{Rad} \operatorname{ccSTP} / g \\
\left(* 10^{-6}\right)\end{array}$ & $\begin{array}{c}A r^{40} \text { Atm } \\
(\%)\end{array}$ & $\begin{array}{l}\text { Edad } \\
(\mathrm{Ma})\end{array}$ & $\begin{array}{c}\text { Error Max } \\
(2 \sigma-M a)\end{array}$ \\
\hline $\begin{array}{c}\text { CNP } \\
\text { Negro Peinado }\end{array}$ & Roca Total & 3,2714 & 0,6783 & 66,02 & 1,14 & 456,6 & 9,2 \\
\hline $\begin{array}{c}\text { QP4 } \\
\text { Negro Peinado }\end{array}$ & $(<2 \mu \mathrm{m})$ & 3,6932 & 1,8546 & 75,62 & 3,82 & 462,6 & 13,6 \\
\hline $\begin{array}{c}\mathbf{5 1 7} \\
\text { Negro Peinado }\end{array}$ & $(<2 \mu \mathrm{m})$ & 4,7644 & 0,5000 & 73,48 & 2,91 & 358,9 & 6,9 \\
\hline $\begin{array}{c}\text { LD6 } \\
\text { La Aguadita }\end{array}$ & $(<2 \mu \mathrm{m})$ & 4,0174 & 1,4316 & 76,78 & 4,02 & 435,2 & 11,6 \\
\hline Filonita & Roca Total & 3,2988 & 0,5000 & 64,56 & 1,39 & 444,3 & 8,3 \\
\hline
\end{tabular}

\subsection{Formación La Aguadita}

La fracción $<2 \mu \mathrm{m}$ de la muestra LD6 está compuesta predominantemente por illita $(89 \%)$ y clorita $(9 \%)$, con esmectita $(3 \%)$, cuarzo y albita subordinados (Fig. 6c). El valor de IK medido en esta muestra es de $0,26 \Delta^{\circ} 2 \theta$ y corresponde al límite entre la anquizona intensa y la epizona (Tabla 3). Para esta muestra el análisis K-Ar arrojó un valor de $435 \pm 12$ Ma (Tabla 4).

\subsection{Faja milonítica Angulos}

La mineralogía de la filonita analizada (Fil), establecida mediante microscopía óptica de transmisión, se compone de cuarzo, plagioclasa, feldespato potásico, muscovita, clorita y biotita (Fig. $5 \mathrm{~g}$ y h). Los porfidoclastos son escasos y están constituidos por agregados de cuarzo y micas de tamaño inferior a los $0,1 \mathrm{~mm}$. La matriz es abundante y se compone de granos $<0,01 \mathrm{~mm}$ de muscovita, cuarzo y feldespato (Dávila, 2001). La edad obtenida para esta faja es de $444 \pm 8 \mathrm{Ma}$ (Tabla 3 ).

\section{Discusión}

\subsection{Datación K-Ar de eventos metamórficos de bajo grado}

La interpretación de resultados geocronológicos obtenidos por el método K-Ar en rocas metamórficas depende principalmente de la temperatura alcanzada por el evento metamórfico y de la temperatura de cierre del sistema del mineral empleado en la datación (Adams et al., 1999; Adams, 2003; Adams y Maas, 2004). En general, se considera que la temperatura de cierre de la muscovita es de $350^{\circ} \mathrm{C}$ (Jäger, 1979; Cliff, 1985; McDougall y Harrison, 1999), aunque esta temperatura puede variar como consecuencia de la deformación, presencia 
de fluidos, variaciones en la composición de los minerales, el tamaño de grano, y las tasas de enfriamiento (Dahl, 1996; Villa, 1997). El sistema K-Ar es ampliamente utilizado para establecer edades de episodios diagenéticos o de metamorfismo de bajo grado en rocas que durante su historia posdepositacional no han superado las temperaturas de cierre mencionadas (e.g., Aronson y Hower, 1976; Lee et al., 1986; Clauer y Chaudhuri, 1999). Asimismo, en la interpretación de edades K-Ar sobre illita en secuencias progradas, es importante tener en cuenta que el equilibrio isotópico alcanzado en el metamorfismo incipiente puede ser incompleto (Clauer et al., 1995; Belmar et al., 2004). La heterogeneidad química e isotópica de estas rocas (Lee et al., 1986; López Munguira y Nieto, 1999; Do Campo y Nieto, 2003; Abad et al., 2006; Kralik, 1983; Hay et al., 1988) depende, en gran medida, del mecanismo mediante el cual se hayan formado los filosilicatos autigénicos y del grado metamórfico alcanzado por las secuencia. Estas condiciones de heterogeneidad que derivan de metaestabilidad son importantes en rocas diagenéticas y de anquizona débil, mientras que, a medida que aumenta el metamorfismo, las edades obtenidas sobre la roca total y sobre la fracción $<2 \mu \mathrm{m}$ (compuesta totalmente $\mathrm{o}$ en forma predominante por micas autigénicas o transformadas) convergen paulatinamente y se acercan al equilibrio termodinámico. Algunos autores como Dong et al. (1997) y Clauer y Chaudhuri (1999) consideran que para lograr la homogeneización del sistema isotópico K-Ar en las metapelitas son necesarias temperaturas correspondientes al límite anquizona-epizona. Al respecto Dallmeyer y Takasu (1992) consideran que el reequilibrio ('reseteo') del sistema K-Ar en las pizarras se completaría en la anquizona más alta. De acuerdo a Hunziker et al. (1986), la pérdida total del Ar heredado en la fracción $<2 \mu \mathrm{m}$ se produce a temperaturas de $\sim 260 \pm 30^{\circ} \mathrm{C}$.

\subsection{Interpretación de las edades K-Ar obtenidas}

Las condiciones establecidas a partir de los análisis cristaloquímicos y cristalográficos en minerales neoformados y transformados para el episodio $\mathrm{M} 1_{\mathrm{NP}}-\mathrm{D} 1_{\mathrm{NP}}$ de la Formación Negro Peinado, permitirían desvincular las edades K-Ar obtenidas de procesos asociados a la intrusión de los granitoides ordovícicos. En la muestra CNP, la presencia de biotita blástica indica temperaturas cercanas a los $400^{\circ} \mathrm{C}$ (cf. Bucher y Frey, 1994) para el clímax del metamorfismo, que superarían las temperaturas de cierre del sistema K-Ar para las fases minerales portadoras de $\mathrm{K}^{+}$presentes (predominantemente biotita y muscovita, con ausencia de feldespato potásico). Esto permitiría suponer que la homogeneización del sistema K-Ar habría sido alcanzada y, en consecuencia, que la edad K-Ar obtenida sobre roca total de $457 \pm 9$ Ma representaría la edad del episodio metamórfico que afectó a la unidad o, en su defecto, una edad de enfriamiento ligeramente más joven. Por su parte, la edad obtenida para la fracción $<2 \mu \mathrm{m}$ de la muestra QP4 (463 $\pm 14 \mathrm{Ma}$, error $1,85 \%$ ) también sería representativa del episodio metamórfico principal. Estas dos edades, coincidentes dentro del rango de error, permiten acotar al Ordovícico Medio-Tardío el episodio metamórfico-deformacional $\mathrm{M} 1_{\mathrm{NP}}-\mathrm{D} 1_{\mathrm{NP}}$ que afecta a la Formación Negro Peinado.

Si bien en nuestro trabajo se analizó una muestra correspondiente a la Formación Achavil, se obtuvo un valor con un error porcentual del orden del $15 \%$, por lo que no fue considerada. Cabe mencionar que Toselli (1978) obtuvo edades K-Ar sobre roca total de entre $495 \pm 15$ y $475 \pm 15$ Ma para muestras de esta unidad aflorantes en la quebrada del río Volcancito (Fig. 3) (unidad atribuida en ese entonces a la Formación Negro Peinado). Estas rocas no muestran evidencias petrográficas ni mineralógicas de haber sido afectadas por un episodio de metamorfismo térmico, como sí ocurre con las cornubianitas de la región del cerro Negro Overo (Fig. 3), por lo que dichas edades podrían, en consistencia con lo sugerido por Toselli (1978), vincularse con un episodio de metamorfismo regional. Dado que los análisis fueron realizados por este autor sobre roca total, es probable que minerales detríticos portadores de $\mathrm{K}^{+}$hayan aportado algo de $\mathrm{Ar}$ heredado, en cuyo caso las edades corresponderían a una edad máxima para el evento metamórfico que afectó a la secuencia. Un metamorfismo en grado anquizona como el que afectó a la Formación Achavil puede no ser suficiente para que se alcance el equilibrio del sistema isotópico K-Ar a nivel de roca total (cf. Clauer y Chaudhuri, 1999).

La edad de $435 \pm 12$ Ma obtenida para la fracción $<2 \mu \mathrm{m}$ en la Formación La Aguadita es aparentemente más joven que la obtenida para el episodio de metamorfismo regional de las unidades de la faja central (formaciones Negro Peinado y Achavil). Esta edad, representativa del episodio metamórfico principal de la unidad, resulta consistente con la pre- 
sencia de circones detríticos de ca. 452 Ma que indican que su depositación y metamorfismo tuvieron lugar con posterioridad a la exhumación parcial del arco magmático oclóyico (Astini y Dávila, 2004), probablemente desarrollado contemporáneamente al episodio de metamorfismo regional que afectó a las formaciones Negro Peinado y Achavil.

Para la Formación La Aguadita una reapertura del sistema isotópico en las illitas durante el desarrollo de la retrodiagénesis debe ser considerada. Estudios realizados en secuencias con una historia posdepositacional similar (e.g., Clauer et al., 1995), indican que las micas generadas durante un episodio progrado no modificarían sus relaciones isotópicas frente a efectos de retrodiagénesis, siempre que este último evento se haya desarrollado a temperaturas mucho menores que la temperatura de cierre de la illita. Clauer et al. (1995) demostraron, además, que cuando los contenidos de esmectita en la fracción $<2 \mu \mathrm{m}$ son menores al 5\%, la edad obtenida no resulta alterada, reflejando correctamente la edad del episodio progrado. En el caso de la Formación La Aguadita, la muestra analizada contiene sólo un 3\% de esmectita (formada a $<180^{\circ} \mathrm{C}$ ), por lo que puede descartarse que la edad obtenida represente una edad de mezcla.

La muestra de la faja milonítica Angulos (fil) habría sido recristalizada en condiciones de facies de esquistos verdes con blástesis de biotita. En este caso, las temperaturas alcanzadas $\left(400^{\circ} \mathrm{C}\right.$, cf. Bucher y Frey, 1994), sumadas al grano fino que presenta la roca, permiten inferir que el sistema isotópico $\mathrm{K}-\mathrm{Ar}$ habría alcanzado el equilibrio durante dicho evento y que la edad de $c a$. 444 Ma obtenida estaría reflejando la del episodio de deformación que generó la faja y no una edad vinculada al protolito. Esta edad resulta consistente con la relación estratigráfica entre la faja y la Formación La Aguadita. En el caso de existir feldespatos relictos (desde la cristalización del granito original) que hubieran preservado parte del Ar radiogénico acumulado en la historia previa a la faja, la edad de 444 Ma sería una edad de mezcla, que representaría una edad máxima para su desarrollo. Dadas las bajas temperaturas de cierre de este mineral $\left(150-350^{\circ} \mathrm{C}\right.$, Reiners et al., 2005) es probable que sus relaciones isotópicas reflejen la historia metamórfica de la roca.
La edad de $359 \pm 7$ Ma obtenida para la muestra 517, correspondiente a los afloramientos de la Formación Negro Peinado, ubicados dentro de la zona de cizalle Las Trancas, podría vincularse al episodio $\mathrm{M} 2_{\mathrm{NP}}-\mathrm{D} 2_{\mathrm{NP}}$ al Devónico Tardío-Carbonífero Temprano. Para este episodio se determinaron condiciones de anquizona intensa, por lo cual es difícil discernir si el sistema isotópico K-Ar alcanzó la puesta a cero en forma total o solo parcialmente. Cabe mencionar que el granito Loma Colorada adyacente, correspondiente a la serie magmática carbonífera (cf. granitos postfamatinianos de Dahlquist et al., 2005b), podría haber afectado térmicamente a esta muestra. Si bien no existen evidencias texturales a favor de un metamorfismo de baja presión, para descartar o corroborar sus posibles efectos, deben llevarse a cabo análisis cristaloquímicos y cristalográficos de mayor detalle, como los realizados en muestras de las formaciones Negro Peinado, Achavil y La Aguadita.

\section{Edades del metamorfismo en un contexto regional}

El ciclo orogénico oclóyico es evidenciado por procesos de sedimentación, deformación, metamorfismo y magmatismo que tuvieron lugar durante el Ordovícico a lo largo del margen occidental de Gondwana. Si bien este ciclo es reconocido desde el Perú hasta la Patagonia (e.g., Lucassen y Franz, 2005; Rapela et al., 2005; Chew et al., 2007) y asociado con un orógeno acreccional, sólo en el segmento andino central (Fig. 7), alineado con el cinturón de Famatina, ha sido vinculado con la colisión del terreno Precordillera (Astini y Dávila, 2004). Dentro de los eventos metamórficos que tuvieron lugar en el retroarco de la placa superior de este segmento, los mejor preservados y más estudiados son los que afectaron las rocas que hoy forman parte de la Sierra de San Luis (Sierras Pampeanas Orientales, Fig. 7), constituida por los complejos metamórficos Nogolí, Pringles y por las filitas de la Formación San Luis. En el Complejo Metamórfico Nogolí, edades de entre 458 2 Ma y 478 \pm 4 (González et al., 2004; Steenken et al., 2006) fueron atribuidas al episodio metamórfico-deformacional principal que afectó a

FIG. 7. Distribución de edades de metamorfismo vinculadas a las orogenias pampeana, oclóyica y achaliana en el segmento sur de los Andes Centrales de Argentina. LP: cinturón Lules-Puncoviscana; Cho: cinturón Choromoro; Q: Sierra de Quilmes; C: Capillitas; A: Ancasti; V: Velazco; F: Famatina; E: El Espinal; U: Umango; M: Sierra de Maz; VF: Valle Fértil; PP: Pie de Palo; Ch: Chepes y Llanos de La Rioja; SL: Sierras de San Luis; Co: Sierras de Córdoba; SN: Sierra Norte; SPOr: Sierras Pampeanas Orientales; SPOcc: Sierras Pampeanas Occidentales. 


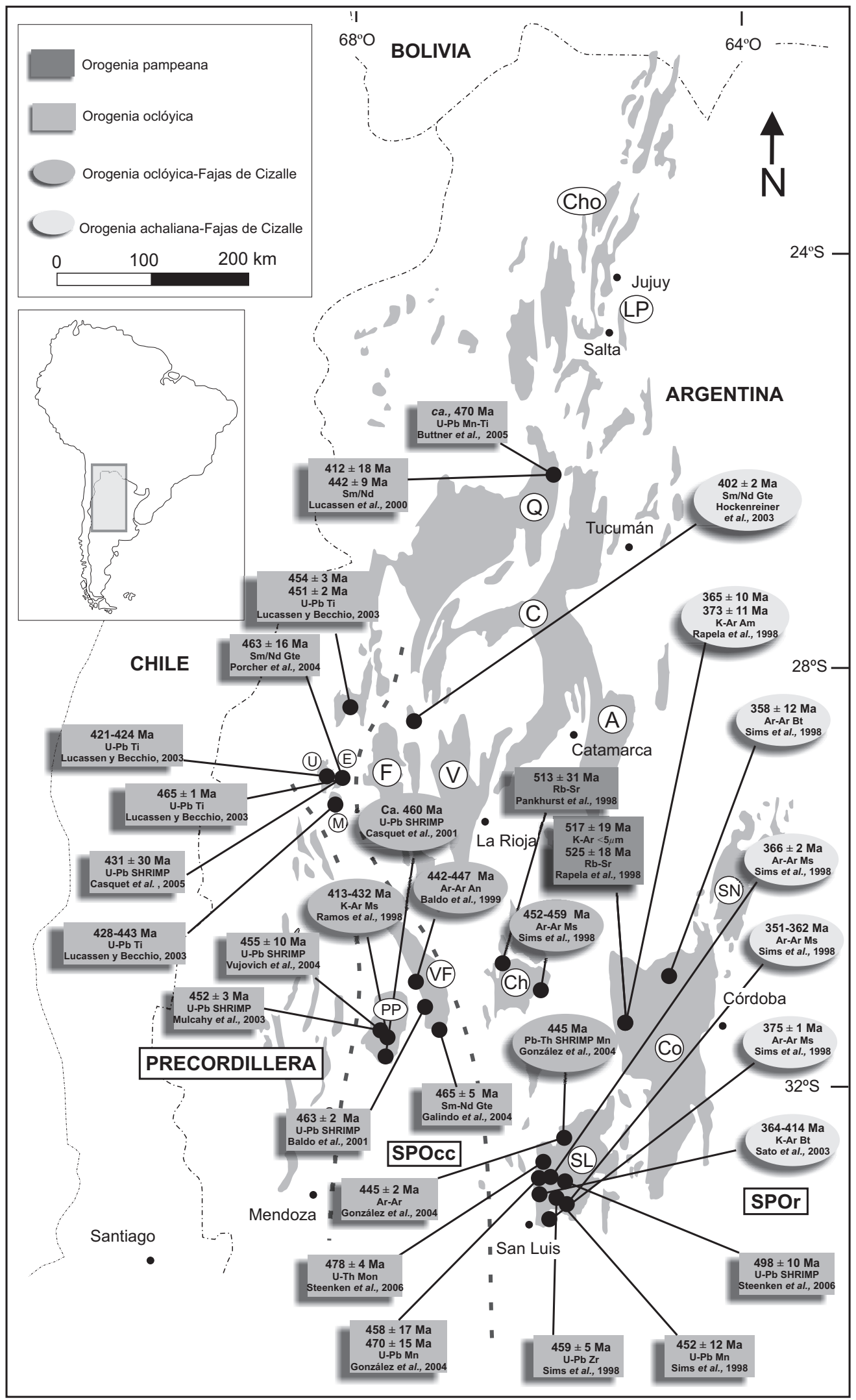


esta secuencia, que no presenta evidencias de haber sido afectada por episodios preoclóyicos. Para el Complejo Metamórfico Pringles, Sims et al. (1998) obtuvieron edades U-Pb de $452 \pm 12$ Ma y $459 \pm 5 \mathrm{Ma}$, mientras que Steenken et al. (2006) obtuvieron una edad algo más antigua (edad U-Pb de ca. 498 \pm 10 $\mathrm{Ma}$ ) a partir de la que sugieren que el episodio de metamorfismo por el que fue afectado este complejo habría comenzado en el Cámbrico Superior y se habría extendido por alrededor de $46 \mathrm{Ma}$. Si bien la edad del metamorfismo y deformación penetrativa que afectó a las filitas de la Formación San Luis no ha podido ser establecida con precisión dado que no se dispone de datos isotópicos, se ha inferido que éstos habrían tenido lugar con antelación al emplazamiento de los granitoides no deformados del Ordovícico Temprano (von Gosen et al., 2002). En la sierra de Chepes, una edad U-Pb SHRIMP de $469 \pm 4$ Ma obtenida para bordes sobrecrecidos de circones en granitoides fue interpretada como producto de un evento de deformación y/o calentamiento desarrollado luego de la cristalización de dichos cuerpos (Dahlquist et al., 2005b; Rapela et al., 2001). Hacia la región norte de las Sierras Pampeanas Orientales, en la sierra de Quilmes (Fig. 1a; Fig. 7), se establecieron edades de entre 412 y $470 \mathrm{Ma}$ (Lucassen et al., 2000; Buttner et al., 2005) para el metamorfismo que afecta a las secuencias metasedimentarias, que fueron interpretadas como producto de un efecto predominantemente térmico desarrollado entre el Ordovícico Medio y el Silúrico en esta región.

Estas edades oclóyicas obtenidas para algunas regiones de las Sierras Pampeanas Orientales, son comparables con las del metamorfismo de bajo grado en Famatina y claramente más jóvenes que las edades cámbricas inferiores ( ca. $530 \mathrm{Ma}$, Rapela et al., 1998) que caracterizan al metamorfismo pampeano en las unidades ubicadas más el este, en las sierras de Córdoba. Particularmente, para las filitas de la región de Los Túneles y para las metapelitas de la región de las Cañas, en la sierra de Chepes (Fig. 7), que han sido correlacionadas con la Formación Puncoviscana, se obtuvieron edades K-Ar (fracción $<0,5 \mu \mathrm{m})$ de $517 \pm 19 \mathrm{Ma}$ y $\mathrm{Rb}-\mathrm{Sr}$ de $525 \pm 18 \mathrm{Ma}$ (Rapela et al., 1998) y edades Rb-Sr de 523 $\pm 47 \mathrm{Ma}$ (Pankhurst et al., 1998), 40 Ma más antiguas que las obtenidas para la Formación Negro Peinado en este trabajo. Si bien no se cuenta con dataciones precisas para el episodio de metamorfismo y deformación en la Formación Puncoviscana, éste está acotado entre el Proterozoico Tardío (Buatois y Mángano, 2003; Adams et al., 2005, 2006) y el Cámbrico Medio (Mángano y Buatois, 2004), sobre la base de evidencias estratigráficas, bioestratigráficas, estructurales y geocronológicas.

En las Sierras Pampeanas Occidentales (Fig. 7), parte de la placa inferior del orógeno en el segmento andino central, las edades asociadas al principal episodio de metamorfismo se vinculan también con la orogenia oclóyica. Para el Complejo Maz (en las Sierras de Maz-Espinal) y la sierra de Umango (Fig. 7), se obtuvieron edades comprendidas entre los $421 \pm 5$ y 466 \pm 1 Ma (Lucassen y Becchio, 2003; Porcher et al., 2004; Casquet et al., 2005). Edades similares fueron obtenidas algo más al sur, en las sierras de Valle Fértil y Las Imanas (463 $\pm 2 \mathrm{Ma}$, Baldo et al., 2001; 465 5 Ma, Galindo et al., 2004). Para la Sierra de Pie de Palo (Fig. 7) Casquet et al. (2001) realizaron análisis U-Pb SHRIMP en circones pertenecientes a rocas metapelíticas, y obtuvieron edades de núcleo de entre 1.000 y $1.200 \mathrm{Ma}$, y edades de bordes de $c a .460 \mathrm{Ma}$, señalando que no existen evidencias de ningún evento metamórfico entre estas dos edades para la región occidental del orógeno. Estas edades de borde son consistentes con las edades U-Pb de 452 \pm 3 Ma y 455 \pm 10 Ma obtenidas para la misma región por Mulcahy et al. (2003) y Vujovich et al. (2004), respectivamente.

De estos resultados se desprende que, tanto en la región gondwánica del orógeno (placa superior del contexto convergente) como en la región del supuesto bloque acrecionado, los principales episodios de metamorfismo tuvieron lugar entre los 498 y $421 \mathrm{Ma}$ (Ordovícico Superior a Silúrico). Algunas edades obtenidas para fajas de cizalle localizadas (Fig. 7), sobre todo en el sector gondwánico del orógeno (Sims et al., 1998; González et al., 2004), pero también en la placa inferior (Ramos et al., 1998; Baldo et al., 1999; Casquet et al., 2001), indican que la deformación oclóyica con cinemática dominantemente inversa y vergencia oeste podría haberse extendido hasta el Silúrico. Cabe señalar que recientemente Thomas y Astini (2007) describen deformación con vergencia oeste afectando la cubierta sedimentaria en la Precordillera septentrional, también acotada al Ordovícico Superior. Considerando este rango, las edades K-Ar presentadas en este trabajo permiten vincular los eventos metamórfico-deformacionales de las unidades con bajo grado del Famatina con la orogenia oclóyica y no con el ciclo pampeano (Cámbrico Temprano 
a Medio) como fue tradicionalmente aceptado. Luego del episodio de metamorfismo regional que en el Ordovícico Medio habría generado el pico registrado en las formaciones Negro Peinado y Achavil en la faja central, se habría producido la migración hacia el este de la faja corrida y plegada en el retroarco oclóyico (Dávila y Astini, 2005), con depositación concomitante de la Formación La Aguadita. Esta última representaría el destechado incipiente del arco magmático y el desarrollo de una cuña clástica sinorogénica (cf. Astini y Dávila, 2004). Es posible que la faja milonítica extensional de Angulos (Dávila, 2003), para la cual se obtuvo una edad K-Ar en roca total de ca. $444 \mathrm{Ma}$, se vincule con adelgazamiento y colapso orogénico luego del máximo engrosamiento del orógeno (e.g., Dewey, 1988; England y Molnar, 1990; Hodges et al., 1998). En este marco, el metamorfismo de la Formación La Aguadita ( $c a .435 \mathrm{Ma}$ ) se asociaría a las etapas finales de la orogenia oclóyica. La aparente inversión en el grado metamórfico, que afecta con mayor intensidad a esta formación, a pesar de ser más joven que las unidades ordovícicas que se ubican en la faja central del Famatina (e.g., Formación Volcancito, Grupos Famatina y Cerro Morado, Figs. 2 y 3), puede explicarse por su posición relativa dentro de la configuración del antepaís.

Los eventos vinculados con la orogenia oclóyica habrían sido sucedidos por episodios desarrollados entre el Silúrico Tardío y el Cárbonífero Temprano (Sato et al., 2003) incluidos dentro del ciclo orogénico achaliano (Sims et al., 1998). En las Sierras Pampeanas Orientales estos episodios se evidencian por el desarrollo de varias zonas de cizalle (Fig. 7; Rapela et al., 1998; Sims et al., 1998; Sato et al., 2003; Höckenreiner et al., 2003). Aun cuando no se conozca la cinemática precisa de varias de estas fajas miloníticas es clara su vinculación con el magmatismo achaliano que habría determinado la intrusión de cuerpos graníticos de 'tipo A' comunes en contextos extensionales (e.g., $340 \pm 3$ Ma, Granito San Blas, Dahlquist et al., 2005b, 2006a, b). La edad K-Ar de $c a .359 \mathrm{Ma}$ para la muestra de la Formación Negro Peinado (517) en la faja de cizalle Las Trancas, ubicada en el límite Devónico-Carbonífero, es consistente con las edades obtenidas para las fajas de cizalle de la región. En el ámbito de la Precordillera, la deformación precordilleránica constituye un equivalente temporal y ha sido reconocida a partir de diversos argumentos estratigráficos (Astini, 1996).
La marcada consistencia entre las edades establecidas para los episodios de metamorfismo en el Famatina, a partir del análisis K-Ar realizado en este trabajo, con la geocronología U-Pb disponible y las evidencias estratigráficas y estructurales discutidas en el texto para este segmento de los Andes centrales, permite concluir que la metodología empleada constituye una herramienta geocronológica independiente y útil a los efectos de validar historias orogénicas complejas.

\section{Conclusiones}

Las dataciones $\mathrm{K}-\mathrm{Ar}$ realizadas permiten vincular los episodios de metamorfismo regional de las unidades con bajo grado del Famatina con la orogenia oclóyica. Las edades obtenidas son más de 40 Ma más jóvenes que las establecidas para el pico de metamorfismo pampeano, característico de la Formación Puncoviscana y equivalentes de alto grado en las sierras Pampeanas Orientales. Las edades metamórficas ordovícicas, junto a la procedencia detrítica de las unidades que componen el 'basamento metamórfico' de la región, permiten diferenciarlo y desvincularlo de las rocas atribuidas al 'Complejo Puncoviscana'. La edad de 463 \pm 14 Ma obtenida para la fracción $<2 \mu \mathrm{m}(\mathrm{QP} 4)$ en la Formación Negro Peinado sería representativa del principal episodio de metamorfismo regional $\left(\mathrm{M} 1_{\mathrm{NP}}\right.$ $-\mathrm{D} 1_{\mathrm{NP}}$ ) por el que fue afectada y resulta consistente, dentro del rango de error, con la obtenida para la misma unidad sobre roca total (CNP, $459 \pm 9 \mathrm{Ma})$. Si bien no se obtuvo una edad confiable para la Formación Achavil, las edades K-Ar previamente obtenidas por Toselli (1978) son comparables con las establecidas en este trabajo para la Formación Negro Peinado. A nivel regional, este episodio se vincularía con el clímax del ciclo orogénico oclóyico durante el cual habría tenido lugar un metamorfismo regional de bajo grado y, localmente, de muy baja presión, asociado con la intrusión de importantes cuerpos batolíticos. El episodio de metamorfismo y deformación registrado en estas unidades afectadas por bajo grado puede correlacionarse con evidencias estratigráficas registradas en la columna del Ordovícico Medio de la región (e.g., discordancia angular entre el Grupo Famatina y el Grupo Cerro Morado). En la Formación La Aguadita, ubicada en el margen oriental del Famatina, el evento metamórfico sería algo más joven y se vincularía con el epílogo de la orogenia oclóyica (ca. $435 \pm 12 \mathrm{Ma}$ ). Efectos proba- 
blemente vinculados a cizalle localizada y/o magmatismo relacionados con el ciclo achaliano ( $c a$. $359 \pm 7$ Ma para la faja de deformación Las Trancas) se superpondrían localmente en algunas fajas de la Formación Negro Peinado. El fuerte acortamiento ocurrido durante el Paleozoico temprano en el Famatina, acentuado por el acortamiento andino, sería responsable de la superposición de estas fajas de rocas ordovícicas (Formación La Aguadita) y preordovícicas (formaciones Negro Peinado y Achavil) que poseen trayectorias de soterramiento y exhumación contrastadas como reflejo de la dinámica en el antepaís oclóyico.

\section{Agradecimientos}

Agradecemos a la Secretaría de Ciencia y Tecnología de la Universidad Nacional de Córdoba (62/03 SECyTUNC), a la Agencia Nacional de Promoción de Ciencia y Tecnología (PICT-2002/07-11741 FONCYT/ANCYT) y al Consejo Nacional de Investigaciones Científicas y Técnicas (PIP-CONICET 5873) que subsidian nuestros proyectos de investigación. Discusiones constructivas con los Dres. F. Dávila y E. Baldo (ambos de la Universidad Nacional de Córdoba), F. Nieto (Universidad de Granada) y las agudas revisiones de los doctores R. Pankhurst, F. Luccasen y un revisor anónimo contribuyeron a mejorar significativamente nuestro trabajo. Agradecemos también a A. Onoe del Centro de Pesquisas Geocronológicas de la Universidad de San Pablo Brasil por su colaboración en los análisis K-Ar. Este trabajo constituye aspectos parciales de la Tesis Doctoral presentada por la primera autora en la UNC.

\section{Referencias}

Abad, I.; Nieto, F.; Gutiérrez-Alonso, G.; Do Campo, M.; López-Munguira, A.; Velilla, N. 2006. Illitic substitution in micas of very low-grade metamorphic clastic rocks. European Journal of Mineralogy 18 (1): 59-69.

Aceñolaza, F.G.; Toselli, A.J. 1988. El Sistema de Famatina, Argentina: Su interpretación como orógeno de margen continental activo. In Congreso Geológico Chileno, No. 5, Actas 1: A55-A67. Santiago.

Aceñolaza, F.G.; Aceñolaza, G. 2005. La Formación Puncoviscana y unidades estratigráficas vinculadas en el Neoproterozoico-Cámbrico Temprano del Noroeste Argentino. Latin American Journal of Sedimentology and Basin Analysis 12 (2): 65-87.

Aceñolaza, F.G.; Miller, H.; Toselli, A.J. 1990. El Ciclo Pampeano en el NoroesteArgentino. Serie Correlación Geológica 4: 227 p. Tucumán.

Aceñolaza, F.G.; Miller, H.; Toselli, A.J. 1996. Geología del Sistema del Famatina, Müncher Geologische Hefte
(Reihe A Allgemeine Geologie) A19: 410 p.

Aceñolaza, F.G.; Miller, H.; Toselli, A.J. 2000. The Pampean and Famatinian Cycles-Superposed orogenic events in West Gondwana. The Geological Evolution of the Andes, Sonderheft ZAG: 337-343.

Aceñolaza, G. 2003. The Cambrian System in Northwestern Argentina: stratigraphical and paleontological framework. Geologica Acta 1: 23-39.

Aceñolaza, G.; Aceñolaza, F. 2000. The Cambrian System in Nothwest Argentina. In Cambrian from the Southern edge (Aceñolaza, G.; Peralta, S.; editors). Instituto Superior de Correlación Geológica (INSUGEO), Miscelánea 6: 46-50.

Adams, C.J. 2003. K-Ar geochronology of Torlesse Supergroup metasedimentary rocks in Canterbury, New Zealand. Journal of the Royal Society of New Zealand, 33 (1): 165-187.

Adams, C.J.; Maas, R. 2004. Age/isotopic characterisation of the Waipapa Group in Northland and Auckland, New Zealand, and implications for the status of the Waipapa Terrane. New Zealand Journal of Geology and Geophysics abstracts 47: 173-187.

Adams, C.J.; Graham, I.J.; Johnston, M.R. 1999. Age and isotopic characterisation of geological terranes in Marlborough Schist, Nelson/Marlborough, New Zealand. New Zealand Journal of Geology and Geophysics 42: 33-55.

Adams, C.J.; Miller, H.; Toselli, A.J. 2005. Rb-Sr age of metasediments of the Puncoviscana Formation, northwest Argentina, and $\mathrm{U}-\mathrm{Pb}$ detrital zircon age evidence for their provenance. Gondwana 12, Conference 35 .

Adams, C.J.; Miller, H.; Toselli, A.J. 2006. Maximum age and provenance area of the Puncoviscana Fm. sediments (NW Argentina) bases on detrital zircon geochronology a pilot study. In Congreso Geológico Chileno, No. 11, Actas 2: 11-14. Antofagasta.

Aronson, J.L.; Hower, J. 1976. Mechanism of burial metamorphism of argillaceous sediments: 2 . Radiogenic argon evidence. Geological Society of America Bulletin 87: 738-744.

Astini, R.A. 1996. Las fases diastróficas del Paleozoico medio en la Precordillera del oeste argentino -evidencias estratigráficas. In Congreso Geológico Argentino, No. 13 y Congreso de Exploraciones e Hidrocarburos, No. 3, Actas 5: 509-526. Buenos Aires.

Astini, R.A. 1999. El Ordovícico del Sistema de Famatina. In Geología del Noroeste Argentino (González Bonorino, G.; Omarini, R.; Viramonte, J.; editores). In Congreso Geológico Argentino, No. 15, Relatorio, 1: 152-158. Salta.

Astini, R.A. 2003. The Ordovician proto Andean basins. In Ordovician fossils of Argentina (Benedetto, J.L.E.; editor). Universidad Nacional de Córdoba: 1-74. Córdoba.

Astini, R.A.; Dávila, F.M. 2004. Ordovician back arc foreland and Ocloyic thrust belt development on 
the western Gondwana margin as a response to Precordillera terrane accretion. Tectonics 23, TC4008, doi:10.1029/2003TC001620.

Astini, R.A.; Dávila, F.M.; Rapela, C.W.; Pankhurst, R.J.; Fanning, C.M. 2003. Ordovician back-arc clastic wedge in the Famatina Ranges: New ages and implications for reconstruction of the Proto-Andean Gondwana Margin. In Ordovician from the Andes (Albanesi, G.L.; Beresi, M.S.; Peralta, S.H.; editors). Serie de Correlación Geológica 17: 375-380.

Astini, R.A.; Dávila, F.; Collo, G.; Martina, F. 2005. La Formación La Aguadita (Ordovícico medio-superior?): Su implicancia en la evolución temprana del Famatina. In Geología de la Provincia de La Rioja (Precámbrico-Paleozoico inferior) (Dahlquist, J.A.; Baldo, E.G.; Alasino, P.H.; editores). Revista de la Asociación Geológica Argentina, Publicación Especial 8: 67-84.

Baldo, E.G.; Saavedra, J.; Rapela, C.W.; Pankhurst, R.J.; Casquet, C.; Galindo, C. 1999. Síntesis geocronológica de la evolución paleozoica inferior del borde sur occidental de Gondwana en las Sierras Pampeanas, Argentina. Acta Geológica Hispánica 32: 17-28.

Baldo, E.G.; Casquet, C.; Rapela, C.W.; Pankhusrst, R.J.; Galindo, C.; Fanning, C.M.; Saavedra, J. 2001. Ordovician metamorphism at the southwestern margin of Gondwana: $\mathrm{P}-\mathrm{T}$ conditions and U-Pb shrimp ages from Loma de Las Chacras, Sierras Pampeanas. In South American Symposium on Isotope Geology, No. 3, Extended Abstracts Volume (CD-ROM): 544-547.

Belmar, M.; Morata, D.; Munizaga, F.; Pérez de Arce, C.; Morales, S.; Carrillo, F.J. 2004. Significance of K-Ar dating of very low-grade metamorphism in TriassicJurassic pelites from the Coastal Range of central Chile. Clay Minerals 39: 151-162.

Buatois, L.A.; Mángano, G. 2003. Early colonization of the deep sea: Ichnologic evidence of deep-marine benthic ecology from the Early Cambrian of nothwest Argentina. Palaios 18: 572-581.

Bucher, K.; Frey, M. 1994. Petrogenesis of metamorphic rocks. 6th. Edition, Complete Revision of Winkler's Textbook. Springer-Verlag: 318. Berlin.

Büttner, S.H.; Glodny, J.; Lucassen, F.; Wemmer, K.; Erdmann, S.; Handler, R.; Franz, G. 2005. Ordovician metamorphism and plutonism in the Sierra de Quilmes metamorphic complex: Implications for the tectonic setting of the northern Sierras Pampeanas (NW Argentina). Lithos 83: 143-181.

Casquet, C.; Baldo, E.; Pankhurst, R.J.; Rapela, C.W.; Galindo, C.; Fanning, C.M.; Saavedra, J. 2001. Involvement of the Argentine Precordillera terrane in the Famatinian mobile belt: U-Pb SHRIMP and metamorphic evidence from the Sierra the Pie de Palo. Geology 29: 703-706.

Casquet, C.; Rapela, C.W.; Pankhurst, R.J.; Galindo, C.; Dahlquist, J.; Baldo, E.G.; Saavedra, J.; González Casado, J.M.; Fanning, C.M. 2005. Grenvillian massif- type anorthosites in the Sierras Pampeanas. Journal of the Geological Society of London 162: 9-12.

Chew, D.M.; Schaltegger, U.; Kosler, J.; Whitehoiuse, M.J.; Gutjahr, M.; Spikings, R.A.; Miskovic, A. 2007. $\mathrm{U}-\mathrm{Pb}$ geochronologic evidence for the evolution of the Gondwanan margin of the north-central Andes. Geological Society of America Bulletin 119 (5-6): 697-711.

Cisterna, G.A.; Cisterna, C.E.; Lisiak, J.H. 1990. Aspectos geológicos del Cerro Los Ramblones, La Rioja, Argentina. In Congreso Geológico Argentino, No. 11, Actas 2: 3-5. San Juan.

Clauer, N.; Chaudhuri, S. 1999. Isotopic dating of very low-grade metasedimentary and metavolcanic rocks: techniques and methods. In Low-grade Metamorphism (Frey, M.; Robinson, D.; editors). Blackwell: 202-226. Oxford.

Clauer N.; Rais, N.; Schaltegger, U.; Piqué, A. 1995. K-Ar systematics of clay-to-mica minerals in a multistage low-grade metamorphic evolution. Chemical Geology, Isotope Geoscience Section 124: 305-316.

Cliff, R.A. 1985. Isotopic dating in metamorphic belts. Journal of the Geological Society of London, 142: 97-110.

Collo, G. 2006. Caracterización petrográfica y termobarométrica de las unidades con bajo grado de metamorfismo de la región central de Famatina. Tesis Doctoral (Inédito), Universidad Nacional de Córdoba, Facultad de Ciencias Exactas, Físicas y Naturales: 262 p.

Collo, G.; Astini, R.A. En prensa. La Formación Achavil: una unidad distinguible dentro del basamento metamórfico de bajo grado del Famatina en la región pampeana de los Andes Centrales. Revista de la Asociación Geológica Argentina.

Collo, G.; Astini, R.A.; Cawood, P.A.; Buchan, C. 2005a. Preliminary detrital ages and stratigraphy for the basement in Famatina, proto-Andean margin of Gondwana. Gondwana 12, Conference 109.

Collo, G.; Do Campo, M.; Astini, R.A. 2005b. Caracterización mineralógica, microestructural e historia posdeposicional de La Formación La Aguadita, Sistema de Famatina, La Rioja, Argentina. Revista Mexicana de Ciencias Geológicas 22 (3): 283-297.

Collo, G.; Dávila, F.M.; Candiani, J.C.; Astini, R.A. 2006. Plegamiento transversal a la deformación oclóyica en rocas pre-ordovícicas del Sistema de Famatina. Revista de la Asociación Geológica Argentina 61 (1): 112-117.

Cordani, U.G. 1970. Idade do Vulcanismo no Océano Atlântico Sul. Boletim do Institute Astronomico e Geofisico, Universidade de Sao Paulo 1: 9-75.

Cordani, U.G.; Ulbrich, M.N.C.; Onoe, A.T.; Vinasco, C.J. 2004. Novas determinações de idade pelos métodos $\mathrm{K}-\mathrm{Ar}$ e Ar/Ar para o Arquipélago de Fernando de Noronha. Revista da Facultade de Ciencias, Universidade Eduardo Mondlade 1: 167-178.

Dahl, P.S. 1996. The crystal-chemical basis for Ar reten- 
tion in micas-inferences from interlayer partitioning and implications for geochronology. Contributions to Mineralogy and Petrology 123 (1): 22-39.

Dahlquist, J.A.; Pankhurst, R.J.; Rapela, C.W.; Galindo, C.; Alasino, P.H.; Casquet, C.; Fanning, C.M.; Saavedra, J.; Baldo, E.G.; González-Casado, J. 2005a. New SHRIMP ages in the Sierra de Famatina, NW Argentina: implications for the Famatinian Orogen. Gondwana 12, Conference 123.

Dahlquist, J.A.; Rapela, C.W.; Pankhurst, R.J.; Baldo, E.G.; Saavedra, J.; Alasino, P.H. 2005b. Los Granitoides de la Sierra de Chepes y su Comparación con Granitoides Paleozoicos de Sierras Pampeanas: Implicancias para el Orógeno Famatiniano. In Geología de la Provincia de La Rioja (Precámbrico-Paleozoico inferior) (Dahlquist, J.A.; Baldo, E.G.; Alasino, P.H.; editores). Revista de la Asociación Geológica Argentina, Publicación Especial 8: 87-108.

Dahlquist, J.A.; Pankhurst, R.J.; Rapela, C.W.; Casquet, C.; Fanning, C.M.; Alasino, P.; Báez, M. 2006a. The San Blas Pluton: An example of Carboniferous plutonism in the Sierras Pampeanas, Argentina. Journal of South American Earth Sciences 20 (4): 341-350.

Dahlquist, J.A.; Alasino, P.H.; Galindo, C.; Pankhurst, R.J.; Rapela, C.W.; Saavedra, J.; Casquet, C.; Baldo, E.G.; González-Casado, J.M. 2006b. Evolución magmática del granito Peñón Rosado, Cerro Asperecito, Flanco occidental de la Sierra de Famatina. Revista de la Asociación Geológica Argentina 61 (1): 93-110.

Dallmeyer, R.D.; Takasu, A. 1992. ${ }^{40} \mathrm{Ar} /{ }^{39}$ Ar ages of detrital muscovite and whole-rock slate/phyllite, Narragansett Basin, RI-MA, USA: implications for rejuvenation during low-grade metamorphism. Contributions to Mineralogy and Petrology 110: 515-527.

Dávila, F.M. 2001. Las Milonitas de Angulos: una faja de cizalle dúctil con cinemática normal en el Sistema de Famatina. Revista de la Asociación Geológica Argentina, Publicación Especial 5: 113-116.

Dávila, F.M. 2003. Transecta Estratigráfica-Estructural a los $28^{\circ} 30^{\prime}-28^{\circ} 45^{\prime}$ de Latitud sur, Sierra de Famatina, Provincia de La Rioja Argentina. Tesis Doctoral (Inédito), Universidad Nacional de Córdoba: 516 p.

Dávila, F.M.; Astini, R.A. 2005. La deformación oclóyica en el Famatina y su vinculación con la estructuración del antepaís protoandino. In Geología de la Provincia de La Rioja (Precámbrico-Paleozoico inferior) (Dahlquist, J.; Baldo, E.; Alasino, P.; editores). Asociación Geológica Argentina, Publicación Especial 8 (D): 133-148.

Dávila, F.M.; Astini, R.A. 2007. Cenozoic provenance history of synorogenic conglomerates in western Argentina (Famatina belt): implications for central Andean foreland development. Geological Society of America Bulletin 119 (4): 609-622.

Dávila, F.M.; Astini, R.A.; Schmidt, C.J. 2003. Unravelling 470 m.y. of shortening in the Central Andes and documentation of Type 0 superposed folding,
Famatina Ranges, Western Argentina. Geology 31: 275-278.

De Alba, E. 1979. Descripción geológica de la Hoja 16d, Chilecito, provincia de La Rioja. Servicio Geológico Nacional: $87 \mathrm{p}$.

Dewey, J.F. 1988. Extensional collapse of orogens. Tectonics 7 (6): 1123-1139.

Do Campo, M.; Nieto, F. 2003. Transmition electro microscopy study of very low-grade metamorphic evolution in Neoproterozoic pelites of the Puncoviscana formation (Cordillera Oriental, NW Argentina). Clay Minerals 38: 459-481.

Dong, H.; Hall, C.M.; Halliday, A.N.; Peacor, D.R.; Merriman, R.J.; Roberts, B. 1997. ${ }^{40} \mathrm{Ar} /{ }^{39} \mathrm{Ar}$ illite dating of Late Caledonian (Acadian) metamorphism and cooling of K-bentonites and slates from Welsh Basin, U.K. Earth and Planetary Science Letters 150 (3-4): 337-351.

Durand, F.R.; Toselli, A.J.; Aceñolaza, F.G.; Lech, R.G.; Pérez, W.A.; Lencina, R. 1990. Geología de la sierra de Paimán, Provincia de La Rioja, Argentina. In Congreso Geológico Argentino, No. 10, Actas 2: 15-18. San Juan.

England, P.; Molnar, P. 1990. Surface uplift, uplift of rocks, and exhumation of rocks. Geology 18: 1173-1177.

Galindo, C.; Murra, J.; Baldo, E.; Casquet, C.; Rapela, C.W.; Pankhurst, R.J.; Dahlquist, J. 2004. Datación Sm-Nd del metamorfismo en la Sierra de la Imanas (Sierras Pampeanas Occidentales, Argentina). Geogaceta $35:$ 75-78.

González, P.D.; Sato, A.M.; Llambias, E.J.; Basei, M.A.S.; Vlach, S.R.F. 2004. Early Paleozoic structural and metamorphic evolution of Western Sierras de San Luis (Argentina), in relation to Cuyania accretion. Gondwna Research 7 (4): 1157-1170.

Gradstein, F.M.; Ogg, J.G.; Smith, A.G.; Agterberg, F.P.; Bleeker, W.; Cooper, R.A.; Davydov, V.; Gibbard, P.; Hinnov, L.; House, M.R.; Lourens, L.; Luterbacher, HP.; McArthur, J.; Melchin, M.J.; Robb, L.J.; Shergold, J.; Villeneuve, M.; Wardlaw, B.R.; Ali, J.; Brinkhuis, H.; Hilgen, F.J.; Hooker, J.; Howarth, R.J.; Knoll, A.H.; Laskar, J.; Monechi, S.; Powell, J.; Plumb, K.A.; Raffi, I.; Röhl, U.; Sanfilippo, A.; Schmitz, B.; Shackleton, N.J.; Shields, G.A.; Strauss, H.; Van Dam, J.; Veizer, J.; van Kolfschoten, Th.; Wilson, D. 2004. A Geologic Time Scale 2004. Cambridge University Press: $610 \mathrm{p}$.

Guggenheim, S.; Bain, D.; Bergaya, F.; Brigatti, M.; Drits, V.; Eberl, D.; Formoso, M.; Galán, E.; Merriman, R.; Peacor, D.; Stanjek, H.; Watanabe, T. 2002. Report of the Association International pour L'Etude Des Argiles (AIPEA) Nomenclature Committee for 2001: Order, Disorder and Crystallinity in Phillosilicates and the use of the 'Crystallinity Index'. Clays and Clay Minerals 50: 406-409.

Guidotti, C.V.; Sassi, F.P. 1986. Classification and Correlation of Metamorphic Facies Series by Means of Muscovite $b_{0}$ data from Low-Grade Metapelites. 
Neues Jahrbuch für Mineralogie Abhandlungen 153 (3): 363-380.

Hay, R.L.; Lee, M.; Kolata, D.R.; Matthews, J.C.; Morton, J.P. 1988. Episodic potassic diagenesis of Ordovician tuffs in the Mississippi Valley area. Geology 16: 743-747.

Höckenreiner, M.; Söllner, F.; Miller, H. 2003. Dating the TIPA shear zone: an Early Devonian boundary between the Famatinian and Pampean systems (NW Argentina). Journal of South American Earth Sciences 16: 45-66.

Hodges, K.; Bowring, S.; Davideck, K.; Hawkins, D.; Krol, M. 1998. Evidence for rapid displacement in Himalayan normal faults and the importance of tectonic denudation in the evolution of mountain ranges. Geology 26: 483-486.

Hunziker, J.C.; Frey, M.; Clauer, N.; Dallmeyer, R.; Friedrichsen, H.; Flehming, W.; Hochstrasser, K.; Roggwiler, P.; Schwander, H. 1986. The evolution of illite to muscovite: Mineralogical and isotopic data from the Glarus Alps, Switzerland. Contributions to Mineralogy and Petrology 92: 157-180.

Jäger, E. 1979. Introduction to geochronology. In Lectures in Isotope Geology (Jäger, E.; Hunziker, J.C.; editors). Springer: 1-12. Berlin.

Kisch, H.J. 1991. Illite cristallinity: recommendations on sample preparation, $\mathrm{X}$-ray diffraction setting and interlaboratory standards. Journal of Metamorphic Geology 6: 665-670.

Kralik, M. 1983. Interpretation of K-Ar and Rb-Sr data from fine fractions of weakly metamorphosed shales and carbonates rocks at the base of the Northern Calcareous alps (Salzburg, Austria). Tschermaks Mineralogische und Petrographische Mitteilungen 32: 49-67.

Kübler, B. 1968. Evaluation quantitative du métamorphisme par la cristallinité de I'llite. Bulletin du Centre de Recherches de Pau-SNPA 2 : 385-397.

Lee, H.J.; Peacor, D.R.; Lewis, D.D.; Wintsch, R.P. 1986. Evidence for syn tectonic crystallization for the mudstone to shale transition at Lehigh Gap, Pennsylvania, USA. Journal of Structural Geology 8: 767-780.

López Munguira, A.; Nieto, F. 1999. HRTEM-AEM study of very low-grade metamorphic evolution in Cambrian sandstones and shales (SW Spain, Ossa-Morena Zone). Clays and Clay Minerals 48: 213-223.

Lucassen, F.; Becchio, R. 2003. Timing of high-grade metamorphism: Early Paleozoic U-Pb formation ages of titanite indicate long-standing high-T conditions at the western margin of Gondwana (Argentina, 26-29 ${ }^{\circ} \mathrm{S}$ ). Journal of Metamorphic Geology 21: 649-662.

Lucassen, F.; Franz, G. 2005. The early Paleozoic Orogen in the CentralAndes: a non-collisional orogen comparable to the Cenozoic high plateau? In Terrane processes at the margins of Gondwana (Vaughan, A.P.M.; Leat, P.T.; Pankhurst, R.J.; editors). Geological Society of London, Special Publications 246: 257-272.
Lucassen, F.; Becchio, R.; Wilke, H.G.; Franz, G.; Thirlwall, M.F.; Viramonte, J.; Wemmer, K. 2000. Proterozoic-Paleozoic development of the basement of the Central Andes (18-26 $\left.6^{\circ} \mathrm{S}\right)$-a mobile belt of the South American craton. Journal of South American Earth Sciences 13 (8): 697-715.

Mángano, M.G.; Buatois, L.A. 2004. Integración de estratigrafía secuencial, sedimentología e icnología para un análisis cronoestratigráfico del Paleozoico inferior del noroeste argentino. Revista de la Asociación Geológica Argentina 59: 273-280.

Massonne, H.-J.; Szpurka,Z. 1997. Thermodynamic properties of white micas on the basis of high-pressure experiments in the systems $\mathrm{K} 2 \mathrm{O}-\mathrm{MgO}-\mathrm{Al}_{2} \mathrm{O}_{3}-\mathrm{SiO}_{2}$ $\mathrm{H}_{2} \mathrm{O}$ and $\mathrm{K}_{2} \mathrm{O}-\mathrm{FeO}-\mathrm{Al}_{2} \mathrm{O}_{3}-\mathrm{SiO}_{2}-\mathrm{H}_{2} \mathrm{O}$. Lithos 41 : 229-250

McDougall, I.; Harrison, T.M. 1999. Geochronology and Thermochronology by the ${ }^{40} \mathrm{Ar} /{ }^{39} \mathrm{Ar}$ Method. United Kingdom, Oxford University Press: 269 p. Oxford.

Merriman, R.J. 2002. Contrasting clay mineral assemblages in British Lower Palaeozoic slate belts: the influence of geotectonic setting. Clay Minerals 37: 207-219.

Merriman, R.J. 2005. Clay minerals and sedimentary basin history. European Journal of Mineralogy 17: 7-20.

Merriman, R.J.; Frey, M. 1999. Patterns of very low-grade metamorphism in metapelitic rocks. In Low Grade Metamorphism (Frey, M.; Robinson, D.; editors). Blackwell Science: 61-107. Cambridge.

Moore, D.M.; Reynolds, R.C. 1997. X-Ray diffraction and the identification and analysis of clay minerals. Oxford University Press: 378 p. Oxford, New York.

Mulcahy, S.R.; McClelland, W.C.; Roeske, S.M.; Vujovich, G.I.; Cain, J.C. 2003. U-Pb circón análisis from the Western Sierras Pampeanas, Northwest Argentina: Evidence for a complex proterozoic through Silurian tectonic history. Geological Society of America Annual Meeting, Resúmenes 35: 344.

Pankhurst, R.J.; Rapela, C.W. 1998. The Proto-Andean margin of Gondwana: an introduction. In The ProtoAndean margin of Gondwana (Pankhurst, R.J.; Rapela C.W.; editors). Geological Society London Special Publications 142: 1-9.

Pankhurst, R.J.; Rapela, C.W.; Saavedra, J.; Baldo, E.; Dahlquist, J.; Pascua I.; Fanning, C.M. 1998. The Famatinian magmatic arc in the central Sierras Pampeanas: an Early to Mid-Ordovician continental arc on the Gondwana margin. In The Proto-Andean margin of Gondwana (Pankhurst, R.J.; Rapela, C.W.; editors). Geological Society London Special Publications 142: 343-367.

Pankhurst, R.J.; Rapela, C.W.; Fanning, C.M. 2000. Age and origin of coeval TTG, I- and S- type granites in the Famatinian belt of NW Argentina. Transaction of the Royal Society Edinburgh, Earth Sciences 91: 151-168.

Porcher, C.C.; Fernández, L.A.D.; Vujovich, G.I.; Chernicoff, C.J. 2004. Thermobarometry, Sm/Nd ages and geophysical evidence for the location of the 
suture zone between Cuyania and Pampia terranes. Gondwana Research 7: 1057-1076.

Ramos, V.A.; Dallmeyer, R.D.; Vujovich, G. 1998. Time constraints on the Early Palaeozoic docking of the Precordillera, central Argentina. In Proto-Andean margin of Gondwana (Pankhurst, R.J.; Rapela, C.W.; editors). Geological Society London Special Publication 142: 143-158.

Rapela, C.W. 2000. The Sierras Pampeanas of Argentina: Paleozoic building of the southern Proto-Andes. In Tectonic Evolution of South America (Cordani, U.G.; Milani,E.J.; ThomazFilho,A.; Campos, D.A.; editors). International Geological Congress, No. 31: 381-387.

Rapela, C.W.; Pankhurst, R.J.; Casquet, C.; Baldo, E.; Saavedra, J.; Galindo, C.; Fanning, C.M. 1998. The Pampean Orogeny of the southern proto-Andes Cambrian continental collision in the Sierras de Córdoba. In The Proto-Andean margin of Gondwana (Pankhurst, R.J.; Rapela, C.W.; editors). Geological Society London Special Publications 142: 181-217.

Rapela, C.W.; Pankhurst, R.J.; Casquet, C.; Baldo, E.; Galindo, C.; Fanning, C.M.; Saavedra, J. 2001. Ordovician metamorphism in the Sierras Pampeanas: new U-Pb SHRIMP ages in central-east Valle Fértil and the Velasco Batholith. South American Symposium on Isotope Geology, No. 3, Extended Abstract Volume (CD): 616-619.

Rapela, C.W.; Pankhurst, R.J.; Fanning, C.M.; Hervé, F. 2005. Pacific subduction coeval with the Karoo mantle plume: the Early Jurassic Subcordilleran Belt of northwestern Patagonia. In Terrane Accretion Processes at the Pacific Margin of Gondwana (Vaughan,A.P.M.; Leat, P.T.; Pankhurst, R.J.; editors), Special Publication of the Geological Society of London 246: 217-239.

Reiners, P.W.; Ehlers, T.A.; Zeitler, P. 2005. Past, present, and future of thermochronology, Reviews in Mineralogy and Geochemistry 58: 1-18.

Rossi, J.N. 1996. El basamento metamórfico del Sistema de Famatina. Müncher Geologische Hefte (Reihe A Allgemeine Geologie), A 19: 23-30. Munich.

Rossi, J.N.; Durand, F.R.; Toselli, A.J.; Sardi, F.G. 1997a. Aspectos estratigráficos y geoquímicos comparativos del basamento metamórfico de bajo grado del Sistema de Famatina, Argentina. Revista de la Asociación Geológica Argentina 52: 469-480.

Rossi, J.N.; Toselli, A.J.; Durand, F.R.; Saravia, J.; Sardi, F.G. 1997b. Significado geotectónico de corneanas piroxénicas en granitos de las sierras de Paimán, Velazco y Famatina, Provincia de La Rioja, Argentina. In Congreso Geológico Chileno, No. 8, Actas 2: 1498-1501. Antofagasta.

Rossi, J.M.; Willner, A.P.; Toselli, A.J. 2002. Ordovician metamorphism of the Sierras Pampeanas, Sistema de Famatina and Cordillera Oriental, Northwestern Argentina. In Aspects of the Ordovician System in Argentina (Aceñolaza, F.G.; editor). Instituto Superior de Correlación Geológica (INSUGEO), Serie Correlación Geológica 16: 225-242.

Saavedra, J.; Toselli, A.J.; Rossi, J.N.; Pellitero, E.; Durand, F.R. 1998. The Early Palaeozoic magmatic record of the Famatina System: a review. In The Proto-Andean margin of Gondwana (Pankhurst, R.J.; Rapela, C.W.; editors). Geological Society London, Special Publications 142: 283-295.

Sato, A.M.; González, P.D.; Llambías, E.J. 2003. Evolución del orógeno famatiniano en la sierra de San Luis: magmatismo de arco, deformación y metamorfismo de bajo a alto grado. Revista de la Asociación Geológica Argentina 58: 487-504.

Sims, J.P; Ireland, T.R.; Camacho, A.; Lyons, P.; Pieters, P.E.; Skirrow, R.G.; Stuart-Smith, P.G.; Miró, R. 1998. U-Pb, Th-Pb and Ar/Ar geochronology from the southern Sierras Pampeanas, Argentina: implications for the Palaeozoic tectonic evolution of the western Gondwana margin. In The Proto-Andean margin of Gondwana (Pankhurst, R.J.; Rapela, C.W.; editors). Geological Society London Special Publications, 142: 259-296.

Steenken, A.; Siegesmund, S.; López de Luchi, M.G.; Feri, R.; Wemmer, K. 2006. Neoproterozoic to Early Palaeozoic events in the Sierra de San Luis: implications for the Famatinian geodynamics in the Eastern Sierras Pampeanas (Argentina). Journal of the Geological Society 163: 965-982.

Thomas, W.A.; Astini, R.A. 2007. Vestiges of an Ordovician west-vergent thin-skinned Ocloyic thrust belt in the Argentine Precordillera, southern Central Andes. Journal of Structural Geology 29 (8): 1369-1385.

Toselli, A.J. 1975. Contribución al conocimiento geológico de la región de Volcancito, sierra de Famatina, Provincia de La Rioja. Tesis Doctoral (Inédito), Universidad Nacional de Córdoba, Facultad de Ciencias Exactas, Físicas y Naturales: 170 p.

Toselli, A.J. 1978. Edad de la Formación Negro Peinado, Sierra de Famatina, La Rioja. Revista de la Asociación Geológica Argentina 33: 86-89.

Toselli, A.J.; Durand, F.R.; Rossi de Toselli, J.; Saavedra, J. 1996. Esquema de evolución geotectónica y magmática eopaleozoica del Sistema de Famatina y sectores de Sierras Pampeanas. In Congreso Geológico Argentino 13 y Congreso de Exploración de Hidrocarburos 3, Actas 5: 443-462. Buenos Aires.

Verdecchia, S.O.; Baldo, E.; Benedetto, L.; Borghi, P. 2007. The first shelly faunas from metamorphic rocks of the Sierras Pampeanas (La Cébila Formation, Sierra de Ambato, Argentina): age and paleogeographic implications. Ameghiniana 44: 493-498.

Villa, I.M. 1997. Direct determination of ${ }^{39} \mathrm{Ar}$ recoil distance. Geochemica et Cosmochemica Acta 61: 689-91.

von Gosen, W.; Loske, W.; Prozzy, C. 2002. New isotopic dating of intrusive rocks in the Sierra de San Luis 
(Argentina): implications for the geodynamic history of the Eastern Sierras Pampeanas. Journal of South American Earth Sciences 15: 237-250.

Vujovich, G.I.; van Staal, C.R.; Davis, W. 2004. Age constraints on the tectonic evolution and provenance of the Pie de Palo Complex, Cuyania composite terrane, and the Famatinian Orogeny in the Sierra de Pie de Palo, San Juan, Argentina. Gondwana Research 7 (4): 1041-1056.

Warr, L.N.; Rice, A.H.N. 1994. Interlaboratory standardization and calibration of clay mineral cristallinity and cristallite size data. Journal of Metamorphic
Geololgy 12: 141-152.

Zimmermann, U. 2003. Provenance study on Neoproterozoic rocks of NW Argentina: Puncoviscana Formation-first results. In Congreso Geológico Chileno, No. 10, Actas, CD-ROM. Concepción.

Zimmermann, U. 2005. Provenance studies of very low to low-grade metasedimentary rocks of the Puncoviscana Complex, northwest Argentina. In Terrane Processes at the margins of Gondwana (Vaughan, A.P.M.; Leat, P.T.; Pankhurst, R.J.; editors). Geological Society London, Special Publications 246: 381-416.

Manuscrito recibido: marzo 12, 2007; aceptado: noviembre 13, 2007. 